\title{
FORTUNA, FATALISMO, LIBERTAD. EL GIRO MAQUIAVELIANO
}

\author{
Juan Manuel FORTE
}

Abstract: The main concern of this article is the analysis of Machiavelli's notion of fortune, intimately connected to his notion of virtue and his understanding of politics. The first objetive is to evaluate the essential distinction between fortune in universale and fortune "in particulare". I will claim that almost all scholars have confused this crucial Machiavellian distinction, and it is therefore a source of inaccuracies and misinterpretations. The second objective is to outline the theoretical limitations of some naturalistic and astrological interpretations of Machiavelli's concept of fortune. The third objective will be to argue that it is impossible to decide whether Machiavelli is compromised with a conception of fortune as simply tyche (in the sense of subjective ignorance of the causes implied in an effect), or rather as automäton (in the Aristotelian meaning of objetive indeterminacy and accidental causes). Lastly, I will try to evaluate the importance of the relevance argued by some scholars - of certain correspondences between the Florentine's naturalism and the "modernity" of his political thought.

Repetidamente se ha señalado la importancia que la noción de fortuna tiene en la obra de Maquiavelo. De hecho, no ha faltado quien ha querido hacer gravitar en torno a la dicotomía virtud/fortuna una de las principales novedades teóricas maquiavelianas ${ }^{1}$. Además, la cuestión de la fortuna apare-

1 Para la importancia del concepto de fortuna en Maquiavelo puede cotejarse, por ejemplo, el artículo de T. FLANAGAN: The Concept of Fortune in Machiavelli. Essays on Machiavelli's Philosophy, en "The Political Calculus", Parel et alli, Toronto 1992, y en particular las pp. 1503. También Sasso, Storia del suo pensiero politico. Il Pensiero Politico, Bologna 1993, pp. 215 , 226, 224-5 et passim. 
ce como uno de esos nudos gordianos de los textos maquiavelianos que perpetúan una polémica sin aparente solución. Mi propósito en lo que sigue es examinar la conceptualización de la fortuna ( $e$, inevitablemente, de ciertas cuestiones que gravitan en torno a ella) siguiendo el orden cronológico de los textos más significativos de la obra maquiaveliana. Es quizá un exceso de ambición pretender una mejor elucidación de un problema de la historia del pensamiento en el que tantos autores de talento y erudición han entrado anteriormente. Puede ser también que los textos maquiavelianos conduzcan inevitablemente a la indefinición o la ambigüedad. En todo caso, nos conformaríamos, con señalar, desde una perspectiva que juzgamos muy poco aprovecha$\mathrm{da}$, las dificultades que los textos del florentino plantean y que, a nuestro modo de ver, han sido dejadas de lado o no han sido suficientemente esclarecidas por los autores que se han ocupado del problema.

Por último, inevitable será abordar algunas de las posibles implicaciones de nuestro examen. De estas últimas destaco al menos un grupo: las cuestiones de la originalidad maquiaveliana en el ámbito de la dicotomía virtud / fortuna y la, últimamente tan debatida, "modernidad" de los textos maquiavelianos.

\section{La cuestión de la fortuna en Maquiavelo}

No es difícil comprender por qué Maquiavelo concede tanta importancia a la cuestión de la fortuna en su obra. Difícilmente puede hallarse un término más ubicuo en los tratados del florentino, ni puede hallarse una cuestión tan persistente como ésta. Innecesario quizá recordar que este protagonismo de la fortuna, que encontramos también en tantos otros escritores renacentistas, tiene que ver con un conjunto de circunstancias históricas que coinciden en la Italia del Renacimiento. Para empezar, la recuperación del pensamiento clásico, y la importancia adquirida por el pensamiento astrológico y hermético. Innecesario puede ser recordar que para la mayoría de autores clásicos ${ }^{2}$, como para la tradición hermética y astrológica, la fortuna tiene una función conceptual más destacada que en la tradición cristiana medieval. El pensamiento cris-

2 Sobre las diferencias entre las principales líneas de pensamiento clásicas y medievales en la concepción de la fortuna y el hado, reenvío al lector a la primer parte del excelente libro de Vincenzo Cioffari, en mi opinión, en muchos aspectos todavía hoy no superado: V. CiOfFARI, Fortune and Fate, from Democritus to St. Thomas Aquinas, Nueva York 1935. 
tiano, sin renunciar en absoluto a pensar el problema de la contingencia, tenía relativamente fácil neutralizar el residuo irracional e inmoral de su teorización del azar a partir de una cosmología providencialista que le venía dada como supuesto insoslayable ${ }^{3}$. Pues bien, es en el decaer de la "Edad del medio" o, si se quiere, en los albores del Renacimiento, que una concepción de la fortuna más o menos autónoma, no reducible a mera función de la Divina providencia (sea concediéndole el grado de entidad existente, como parece suceder en el poema de Dante; o como realidad epistemológica, tal que en el análisis del aquinate), se va configurando ${ }^{4}$.

3 Que la fortuna tienda a ser absorbida por la Divina providencia, y haga las veces de instrumento de justicia (aunque inescrutable para los humanos) en las manos de Dios, aparece ya en De consolatio Philosophiae (Boecio, De Cons. IV, vi). A grandes rasgos fue esta la visión imperante durante el Medievo y que se propaga a partir de autores enciclopédicos como Vicente de Beauvais o Alberto Magno. Partiendo de este último, Santo Tomás por ejemplo asimila la fortuna al casus (Sum. Theol. I 116 1; cf. También I, ii, q. 55, a. 4; q. 110, a. 4 ad I); pero, en línea aristotélica le otorga realidad ontologica al relacionarla con el concursus de la multitudo et diversitas causarum y con las causae per accidens (Cont. Gent. III 74); además, recuerda que la providencia no es en absoluto incompatible con la casualidad: "ordo divinae providentiae exigit quod sit casus et fortuna in rebus." (Ibid.; of tambien In octo libros Physicorum Aristotelis, II, viii). Paparelli, en su análisis de la tradición medieval inspirada en Boecio, hace hincapié en la neta identificación entre fortuna ( $y$ particularmente cuando adversa) y divina providencia en contraposición a el pensamiento maquiaveliano (G. Paparelli, "Virtù e Fortuna nel Medievo, nel Rinascimento e in Machiavellin, en Cultura e Scuola, 1970, pp. 72-89, aquí p. 77). Una síntesis de las líneas principales de contraste entre la fortuna en Boecio, Agustín y Dante respecto de Maquiavelo, también en J. Leeker, Fortuna bei Machiavelli - ein Erbe der Tradition?, "Romanische Forschungen", (1989), 101 (4), pp. 410-414.

4 Puede decirse que la recuperación del mundo pagano no se limitó a ser moda literaria, sino un pathos que, aunque generalmente combinado con el elemento cristiano, se manifiesta en todos los ámbitos, desde la esfera moral al terreno de lo ritual. A este propósito cabe destacar la tradición florentina de los carros alegóricos (en los que, entre otras cosas, se representaba a la diosa Fortuna) como probable inspirador del maquiaveliano Capitolo di Fortuna (ver a este propósito G. Inglese, Capitoli, Roma 1981, pp. 38-40). Por lo demás, es obvio que la tradición humanista, a partir de Petrarca, empieza a tratar sobre la fortuna desde una perspectiva cada vez más mundana, aunque sobre todo en contextos poéricos y autobiográficos. Ya en el siglo XIV aparece un grupo de poetas que a menudo hacen mención al poder de la Fortuna (Federigo Frezzi, Brizzio Viscoti, Suiannozzo Sacchetti, Fra Stoppa dei Bostichi, Bonaccorso Pitti...). Pero tal vez son el De remediis utriusque Fortunae de Petrarca y el De casibus de Boccaccio la mayor referencia literaria en la Florencia del Renacimiento. Durante el siglo XV son celebres sobre todo el De variatate fortunae de Poggio y el trabajo del humanista y papa Pío II (Somnium de fortuna). Como veremos más adelante, cronológica y conceptualmente más cercanas a Maquiavelo son las obras De Fortuna y De rebus coelestibus de Pontano. Para la identificación de las fuentes de la noción de fortuna Maquiaveliana ver sobre todo: A. Gilbert, Machiavellis Prince and Its Forerunners, New York 1938, y G. Papparelli, art. cit. 
Desde la perspectiva concreta de la esfera política, algún autor ha subrayado la conexión entre el republicanismo político y el mundo mercantil de las ciudades italianas y una nueva concepción del tiempo y de la historia abocado a la contingencia ${ }^{5}$; ni ha faltado quien aventurase que es en realidad de ese mundo proto-burgués de las ciudades italianas de donde procede la mundanización del concepto de fortuna y su vaciado de elementos religiosos o providencialísticos ${ }^{6}$.

Pero centrémonos en Maquiavelo. $\mathrm{Y}$ advirtamos antes de nada que el florentino usa el término con múltiples significados, a veces de naturaleza metafórica. No entraremos a desbrozar los numerosos matices que la palabra adquiere a lo largo de su obra, es ésta una tarea que no interesa aquí. Nos limitaremos más bien a trazar los más recurrentes y significativos significados que encontramos en los textos maquiavelianos.

La fortuna aparece a menudo opuesta a la virtud, en este caso, la potencia humana para conocer y determinar el curso de los eventos de acuerdo con sus preferencias e intereses. Así, la oposición entre virtud y fortuna la encontramos en un gran número de capítulos Il principe ( $P$ I; VI; VII; VIII; XI; XIII; XXIV, XXV, XXVI), de los Discorsi, (D I, 4; I, 10; I, 19; I, 25; II, 1;

5 Una de las tesis de Pocock es la de que el pensamiento republicano está esencialmente referido al tiempo, por lo que supone una concepción básicamente historicista. Así, el republicanismo italiano tendería a interpretar el mundo eliminando o marginando los elementos providencialísticos de la tradición cristiana. En este sentido, el tiempo es entendido como la constante fluctuación a la que debe enfrentarse el hacer político y la virtud humana (cf. J.G.A. Pocock, The Machiavellian Moment, Princenton 1975, p. 8). No parece insensato pensar que esta concepción (y al margen de que pueda, extenderse a todos los autores republicanos u otros que no lo son), es asumida y aún radicalizada por Maquiavelo.

6 En efecto, nada despreciable es el papel central que la elite mercantil y financiera tiene en la sociedad italiana y sobre todo en las ciudades de tradición republicana. La economía italiana de la época se halla continuamente sometida a un enorme grado de riesgo y fluctuación que se manifiesta a través de las repentinas pero continuadas crisis financieras. En este sentido no es quizá disparatado afirmar que la fortuna se va configurando en la psicología mercantil italiana como una entidad de la que dependen sus vidas y que los mercaderes italianos desarrollan un concepto de fortuna en términos estrictamente inmanentísticos (Parel, A, J., The Machiavellian Cosmos, Yale 1992, p. 66). Por lo demás, Pocock ha establecido unas sugerentes aunque, en mi opinión, vagas analogías entre las nociones de crédito y fortuna (Pocock, op. cit., ix). Sobre el mundo mercantil y la importancia de la fortuna en Maquiavelo una buena síntesis se halla en las páginas dedicadas a la cuestión por Münkler, H., Machiavelli. Die Begründung des politischen Denkens der Neuzeit aus der Krise der Republik Florenz, Frankfurt 1990, Pp. 211 y 303-4. 
II, 3; II, 30; III, 9; III, 30; III; 31). Por el contrario, la virtud escasea en las Istorie Fiorentine, en donde la fortuna se alza como gran protagonista de la historia de Florencia e Italia. Con todo, también allí Maquiavelo apela ocasionalmente a la contraposición entre fortuna y virtud o prudencia. (IF I, 1; IV, $1 ;$ IV, 26). Cuando la fortuna viene referida a un sujeto político concreto (un individuo, un colectivo, una ciudad), Maquiavelo caracteriza el término fortuna con adjetivos que hacen siempre referencia a la relación entre el sujeto al que se refieren y la dirección o el cariz de los eventos. Por ejemplo, habla a menudo Maquiavelo de buona fortuna o fortuna prospera refiriéndose a determinados hombres particulares $(D I, 4 ; 1,11$; III, 2; III, 31; III, 9; IF, V, 1); o también a ciudades (IF IV, 1): así se habla de cattiva fortuna (D I, 8; III, 31; IFVIII, 10); o de mala fortuna de Florencia (IF III, 2); o de aversa fortuna (IF VIII, 9); de tener inimica la fortuna ( $D$ II, 13); o de la continua malignità della fortuna ( $P$, Dedica); y de la estraordinaria ed estrema malignità ( $P$ VII). De acuerdo con estos últimos textos, no ha faltado quien ha querido acentuar el carácter mitológico y maligno de la Fortuna ${ }^{7}$. Sin embargo, parece obvio que la fortuna maquiaveliana puede decirse buena o mala sólo en un sentido relativo. Me parece que precisamente porque la fortuna es una fuerza que expresa un residuo de irracionalidad viene presentada por Maquiavelo mitológicamente. Usando la metáfora y la figuración, Maquiavelo puede pecar de ambiguo o impreciso; no nos parece, con todo, que esto tenga implicaciones mitológicas e irracionales como las apuntadas por Parel o Flanagan. Si se me permite la comparación, creo que nadie acusaría a Boecio o a Dante de insuficiencia conceptual por hacer uso de la metáfora y del lenguaje figurativo en sus respectivas Consolatio y Commedia. Es cierto que en el caso de Maquiavelo la fortuna puede muchas veces emparentarse con el uso vago que hallamos en autores como Polibio ${ }^{8}$; pero, como

7 Así, Parel señala que la fortuna es para Maquiavelo "una diosas maligna o indiferente al bienestar humano" (Parel, op. cit., p. 66). Y de manera similar, Flanagan crítica que Maquiavelo adopte una concepción pseudo-mítica de la fortuna marginando el elemento racional (art. cit. p. 156).

8 El historiador griego tiende a mitologizar y a convertir a TychA en una Diosa, lo que explica su ambigüedad e imprecisión (Histories XI, 24, 8, XX. 7, 2; XXI, 9; etc.). A este respecto, por ejemplo J. Mazzeo ha subrayado la afinidad entre la fortuna maquiaveliana y la polibiana (J. MAZZEO, Renaissance and Seventeenth-Century Studies, Nueva York 1964, p. 154. Con todo, se debe señalar una clara diferencia entre la fortuna polibiana y el uso vago que adquiere en Maquiavelo: el carácter más acentuadamente teleológico y providencial del historiador griego (Polibio, Histories I, 4, 1; I, 4, 3) está ausente en el escritor florentino. 
veremos, a diferencia del historiador griego, Maquiavelo no se limita a usar una vaga noción de la fortuna en sus escritos, sino que teoriza no sin minuciosidad, en diferentes obras y tiempos, el papel y la naturaleza de la fortuna en el ámbito político.

Si quisiéramos trazar una fórmula provisional, diríamos que la fortuna parece ser lo que la subjetividad humana, individual o colectiva, no puede determinar ni prever: la causa de aquellos efectos imprevistos que inciden en el hacer humano ${ }^{9}$. Es ésta pues una caracterización meramente negativa del concepto, como límite de la potencia humana (individual y colectiva) para prever el curso de los acontecimientos o bien, simplemente, para determinar su dirección. Dejaremos para las conclusiones, si la fortuna es para Maquiavelo mera ignorancia de la causas que provocan los efectos (al modo en que Aristóteles caracteriza la postura democritea), o puede hablarse también de una fortuna en sentido fuerte (como ausencia de causa eficiente determinada), a la manera en que el mismo Aristóteles parece admitir $^{10}$.

Pero asumido este uso de la noción de fortuna (que en cualquier caso no será la única que arrojan los textos maquiavelianos), podemos pasar a examinar los pasajes más importantes en los que Maquiavelo no se limita a utilizar la palabra fortuna con un sentido u otro, sino que entra justamente a caracterizarla en relación a la acción política y la historia. Por orden cronológico, estos pasajes (aunque ocasionalmente mencionaremos otras variaciones sobre la cuestión fuera de éstos) son básicamente cuatro:

- la carta a Soderini de 1506, mejor conocida como Ghiribizzi.

9 A veces lo fortuito, lo imprevisto se refiere a algún ámbito de la actividad humana a la que le es esencial la fortuna, la contingencia. Este es el caso por ejemplo de la guerra y en particular de la batalla. Allan Gilbert ha sefialado a este propósito que este dominio de la fortuna sobre la guerra es un tópico del mundo clásico y del Renacimiento, presente en autores como Cesar, Lorenzo de Medici, o Patricius. (A. Gilbert, op. cit, p. 207). En efecto, dando por sentado una cierto equilibrio de fuerzas, asume que la guerra es por excelencia el reino de lo fortuna, y la acción militar significa la asunción de un riesgo irreductible. Así, Maquiavelo emplea a menudo la locución la fortuna della zuffa (D II, 10; III, 10; IF II, 14; II, 26; IV, 25; VI, 24) para acentuar el componente azaroso intrínseco a toda acción bélica.

10 En torno a la tych $A$ y el autom,ton y las diferencias al respecto entre aristotélicos, epicúreos y estoicos ver el esclarecedor libro de Carlo Diano, Forma y evento. Principios para una interpretación del mundo griego, trad. de C. Rendueles, Madrid 2000, trad. de C. Rendueles, pp. 46-48 y 53-55. 
- el poema Capitolo di Fortuna, dedicado a G. B. Soderini y que se viene datando como poco posterior a los Ghiribizzi ${ }^{11}$.

- el célebre capítulo XXV de Il principe, escrito en torno a 1513.

- los capítulos 8 y 9 del Libro III de los Discorsi, escritos con toda probabilidad después de 1513 y con anterioridad a $1517^{12}$.

\section{Los Ghiribizzi a Piero Soderini}

En los Ghiribizzi, la cuestión de la fortuna aparece introducida a través de una paradoja: ¡cómo es posible que los hombres en política, actuando de un mismo modo, lleguen a tan diversos resultados? y ¿cómo es posible que, en otras ocasiones, actuando de maneras tan opuestas, lleguen a idénticos resultados? En otros términos, ¿por qué, quienes, por ejemplo, se guían siempre por métodos enérgicos y violentos $\mathrm{o}$, al contrario, por una actitud de temporización y medios pacíficos, a veces alcanzan el éxito, a veces un rotundo fracaso? ¿y por qué usando métodos tan diferentes, por ejemplo, una implacable severidad (Aníbal), o una actitud grata y clemente (Escipión el Africano), se obtiene a menudo un mismo resultado?

Maquiavelo empieza respondiendo: de dónde nazca esto «io non so». Pero este "no saber" viene inmediatamente desmentido por una hipótesis. Con

11 "Niccold Machiavelli a Giovan Battista Soderini, Perugia, 13-21 septiembre 1506. Tradicionalmente I Gbiribizzi a Soderini se fechaban en torno a 1512 en Perugia. En los años 70, R. Ridolfi demostró que la carta no pudo ser escrita después de septiembre de 1506. EJ manuscrito de la carta contiene anotaciones en los márgenes y que se citan con las letras griegas a, b, g, d, e, z. En relación con la datación de los Ghiribizzi y el Capitolo di Fortuna son útiles las apreciaciones en nota a pie de página de F. Gaeta (en la edición que utilizo para citar el texto); y el comentario de G. Inglese en su edición del Capitolo di Fortuna (notas 2, 61 y sig).

12 Por lo que se refiere a los Discorsi (D), el Capitolo di Fortuna (CF) y de la Ambizione (CA), Il principe (I) Vita di Castruccio Castracani (VC) cito y traduzco siempre a partir de las ediciones de Giorgio Inglese:

N. MaChIAVELli, Discorsi sopra la prima deca di Tito Livio, ed. de G. Inglese, Milán 1984

N. MaChiavelli, Capitoli, introduzione, ed. crít. de G. Inglese, Roma 1981.

N. MaCHIAVELl, Il principe (De principatibus), ed. de G. Inglese, Turín 1995.

N. Machiavelui, La vita di Castruccio Castracani et altri scrittri, ed. de G. Inglese, Milán 1991.

Respecto de las Istorie fiorentine (IF) utilizo la edición crítica de Plinio Carli: N. Machiavelli, Istorie Fiorentine, texto crit. de P. Carli, II Vols., Florencia 1927. Respecto de los Ghiribizzi sigo las Lettere (L) de acuerdo con la edición de F. Gaeta en N. Machiavelli, Opere, vol. III, Turín 1984. 
todo, no debe concluirse por ello que el «yo no lo sé» tenga un valor puramente retórico. Como veremos, el poema no acaba de librarse nunca de un cierto margen de incertidumbre. De hecho, para empezar, la que Maquiavelo presenta como su hipótesis viene, por oposición al saber, llamada "opinione», esto es, como una conjetura que podría sintetizarse del siguiente modo:

(i) En primer lugar, la naturaleza ha dotado a cada cual con facultades e imaginación particulares por las que los hombres se rigen: "la naturaleza ha becho a los hombres con rostros diferentes, como igualmente los ha dotado de diferente talento $e$ imaginación. De aquí que cada cual se gobierne segrin su talento y fantasía." $(G, 244)$

(ii) En segundo lugar, el mundo humano está en continuo movimiento, en constante fluctuación: "Los tiempos son varios, y los órdenes de las cosas son diferentes.» $(G, 244)$

(iii) Ahora bien, de esta confrontación entre, por un lado, un mundo fluctuante y cambiante $y$, por otro lado, diferentes tipos de hombres que se rigen de acuerdo a su particular talento (ingegno) e imaginación (fantasia), de este encuentro, digo, es de donde se origina que unos prosperen y otros fracasen con diversos o con los mismos modos de proceder.

Tienen buena fortuna los que actúan de acuerdo con la necesidad del momento: "es afortunado quien concuerda [riscontra] su modo de proceder con el curso del tiempo." $(G, 244)$ Por el contrario, es desventurado "quien se disocia [diversifica] en sus acciones del orden del tiempo y de las cosas". (Ibid.)

Ahora bien, Maquiavelo introduce una crucial distinción en ese variar de los tiempos y las cosas. Retengamos esta premisa fundamental para entender los textos maquiavelianos: los tiempos cambian «universalmente» y "particularmente" $(G, 244)$. Se trata ésta de una distinción típica en la literatura astrológica de tradición ptolemaica. Maquiavelo la adopta para distinguir entre aquellos cambios particulares que afectan al área de acción individual, y aquellos cambios "en lo universal" que afectan a las ciudades o regiones. Además, entre individuo y ciudad, tenemos agregados intermedios como son el grupo o la familia (esta última también mencionada en una apostilla al texto) ${ }^{13}$.

13 "Como la fortuna se consume, así se arruina el hombre, la familia, la ciudad; cada uno basa su fortuna en su modo de proceder y todas se consumen, y cuando una se agota se necesita reconquistarla de otro modo. $\left(G, 242,{ }^{*}\right)$ También Dante trata la cuestión específica de la fortuna respecto de ciudades y familias en Par. XVI, 34-154. 
Retomando el hilo de nuestra exposición, puesto que los tiempos cambian particular y universalmente, los hombres, si mantienen su modo de proceder invariable, obtienen unas veces un resultado favorable y otras adverso. Por el contrario, a fin de tener siempre la suerte a favor, los hombres debieran saber cambiar su actitud: individuos y colectivos debieran alternar severidad y humanidad, violencia y clemencia. En otras palabras: si alguien fuese capaz de conocer cuál es la actitud que los tiempos requieren y, a continuación, cambiar su modo de proceder de acuerdo con el signo de los tiempos, siempre tendría buena fortuna. Maquiavelo vuelve en este punto a hacer uso de una fórmula de tradición astrológica: "... y vendría a ser verdad que el sabio gobernase las estrellas y los destinos.» $(G, 244)$ En efecto, nuevamente se trata de una frase de procedencia ptolemaica ${ }^{14}$ y que remite a la posibilidad de una ciencia del futuro de naturaleza astrológico adivinatoria.

Pero el pensador florentino se apresura a negar que pueda existir un hombre capaz de prever el fluctuar de los tiempos: "... no se encuentran estos sabios, en primer lugar porque los hombres tienen la vista corta...." (ibid) ${ }^{15}$. Queda en el aire si el que no se encuentren este tipo de sabios es una cuestión de facto o si, como parece más probable, se trata de alguna imposibilidad necesaria de naturaleza antropológica o gnoseológica. El hecho es que no hay hombres capaces de determinar el fluctuar de los acontecimientos humanos, al menos en todas sus causas y efectos particulares. Por otro lado, la relativa escasez de prudencia en el hombre, en relación con la fuerte y vivaz imaginación, nos persuade fal-

14 Tal y como dirá Parel: «The most celebrated astrological formula of the times 'the wise man will overcome the stars' (vir sapiens dominabitur astris) referred to in both The Prince and the Ghiribizzi is thought to have its origin in the Centiloquiums (Parel, op. cit., 11). En realidad, la idea tolemaica no se encuentra tal cual en Tolomeo aunque sí se halla por ejemplo en Alberto Magno (Physicorum, II, II, 21).

15 Así pues, parece que Maquiavelo niega rotundamente la existencia de un sabio, ni por ciencia astrológica ni de ningún otro tipo, capaz de conocer con seguridad y con antelación el cambio de los tiempos. Maquiavelo estaría aquí confutando expresamente lo que el astrólogo Bartolomeo Vespucci parece atribuirle en una carta de 1504 (cf. $L$, Bartolomeo Vespucci a N. Machiavelli, 4/6/1504, p. 194) Cierto es que Maquiavelo admite en $D I, 56$, la posibilidad de la prognosis y la profecía natural, pero esta prognosis no constituye una ciencia ni desde luego un saber teórico al que deba atenerse el arte de la política, sino más bien un dato a tener en cuenta y a utilizar o manipular con fines políticos (cf. DI, 11). Sasso ha sido quien más insistentemente ha subrayado que el pasaje maquiaveliano se opone, quizá en referencia a Vespucci, a cualquier pretensión astrológica de conocimiento del futuro, cf. Sasso, Machiavelli e gli antichi, vol. II, Milán 1988, pp. 32-35; también en N. Machiavelli, Storia del suo pensiero politico: Il Pensiero Politico, vol. I, Bologna 1993, p. 226, 232-4) 
samente, dice Maquiavelo, de que aquello que nos procuró éxito ayer, nos lo procurará también mañana (esto es, la imaginación nos hace percibir como necesario, lo que en realidad es un nexo contingente y secundum quid). En definitiva, los hombres no varían su modo de proceder en función de sus fantasías, y de ahí que cambie su suerte de acuerdo con el variar de los tiempos.

Por otro lado, la cortedad de la inteligencia humana y el peso de la imaginación no son los únicos defecto en el hombre. Maquiavelo, en otro pasaje de su carta, afirma que, incluso concediendo que los hombres quisieran cambiar de proceder, en realidad, no podrían apartarse de lo que les dicta su propia naturaleza, su carácter e inclinaciones: "...no pudiendo, además [los hombres] gobernar su propia naturaleza." (ibid.) ${ }^{16}$ De esta manera, la fortuna gobierna a los hombres, primero porque éstos son cortos de ingenio y vienen confundidos por su imaginación y, segundo, porque los hombres no pueden ni saben dominar su naturaleza; sus hábitos (esa segunda naturaleza aristotélica), basados en su carácter, les hacen demasiado poco versátiles para contemporizar el zigzag de la fortuna. Vemos pues, que ya en esta primera aproximación a la cuestión de la fortuna, el problema no se articula a partir de la teorización de una entidad externa, sino en la propia estructura de la naturaleza humana. No es difícil sintetizar como se delinea esta articulación relativamente pesimista:

- no se puede prever el cambio de los tiempos (no hay saber astrológico que prediga la contingencia).

- en cualquier caso, el hombre no puede cambiar su comportamiento. $\mathrm{El}$ hombre individual no es, ni sabe ser, un divino camaleón: sus hábitos, lejos de ser, como en la tradición aristotélica, el fundamento de la virtud, son la limitación que lo sitúa a merced de la red tejida por fortuna.

Pero Maquiavelo parece no darse del todo por satisfecho con el callejón teórico al que conduce este planteamiento. A este respecto, aunque no hallamos paliativo aparente en la carta misma, sí lo hallamos en las apostillas escritas en los márgenes del texto. Allí Maquiavelo parece entrever alguna salida a un modo éste de plantear el problema que, como a nadie se le escapará por lo

16 G. Sasso ha enfatizado el carácter esencialmente pesimista del razonamiento maquiaveliano (en vaga oposición al mirabilis chamaleonte de Pico); un pesimismo, añadirá este autor, firmemente racionalista (op. cit., 1993, pp. 233-8). 
dicho hasta aquí, implica un férreo naturalismo y está muy cerca del fatalismo antropológico y político.

El primer posible atenuante a este fatalismo, que se desarrollará con mayor precisión en Il principe, aparece en una apostilla: "Tentar la fortuna, que es amiga de los jóvenes, y cambiar de proceder de acuerdo con los tiempos. Pero no se pueden tener fortificaciones y no tenerlas; no se puede ser cruel y pío.» $(G, 242, \delta)$ Por lo que respecta a ese tentar la fortuna, que no es sino una apología de la audacia 17 frente a la prudencia y la circunspección, dejaremos nuestros comentarios para $I l$ principe donde Maquiavelo retomará la cuestión con más profundidad. Sorprende la segunda parte de la frase ("y cambiar de proceder de acuerdo con los tiemposs) puesto que resulta aparentemente contradictoria con lo dicho hasta ahora. Esta podría relacionarse con lo que se especifica a continuación dentro del texto: que se obtiene reputación aplicando la irreligión y la violencia allí donde los hombres parecen empalagados o hastiados de la dulzura de la paz; y aplicando la religión y la humanidad donde se duelen del reiterarse de los males. Así, las ciudades deben alternar estos dos tipos de políticas de acuerdo con las necesidades que va imponiendo la cualidad de los tiempos $(G, 244-5)$, y de aquí el éxito del uso alterno del binomio crueldad/humanidad $(G, 245)$. Por tanto, bien podemos asumir la posibilidad de ese cambio de proceder en las ciudades, que, si gobernadas por diferentes tipos de hombres y humores, pueden asumir esa naturaleza "camaleónica» que Pico atribuía no al hombre particular, sino al género humano. Pero el texto no se refiere exclusivamente a las ciudades, sino a los hombres en particular. Existe pues una contradicción entre el hombre, que no puede "gobernar su propia naturaleza" del texto principal, y el hombre que debe «cambiar de procedem de la apostilla. Maquiavelo no resuelve en este texto la aparente incoherencia (es obvio que las apostillas implican una nuevo planteamiento aún no plenamente desarrollado). Sólo más tarde veremos que esta contradicción, si bien quizás no enteramente resuelta, será ulteriormente precisada y replanteada.

En otra de las apostillas en los márgenes de la carta a Piero Soderini. Maquiavelo parece aducir otro atenuante al fatalismo al que su propia teoría parece conducir: «En fin, no dar consejos a nadie, ni aceptar consejos de nadie que

17 Un precedente habría que ponerlo en el extendido lema "audentes Fortuna iuvat que se encuentra por ejemplo en la Eneida, X, 284; Seneca, Ad Lucilium, Liber XV, 94, 28. Y una variación en Cicerón (Tusc. II, 11), que éste refiere como un viejo proverbio: "fortes Fortuna iuvats. 
no sean consejos generales; que cada uno haga lo que le dicta su ánimo, y con audacia». $(G, 242, \beta)$ «Atenuante» en la medida en que supone una llamada a la acción frente a la pasividad ante los acontecimientos y puesto que parece implicar que existe al menos una cierta libertad de elección (seguir o no seguir diferentes tipos de consejos). Visto que no podemos apartarnos de nuestra naturaleza, parece apuntar el texto, sigamos nuestras inclinaciones naturales, y sigámoslas con determinación. Aceptemos consejos que sean generales, esto es, sobre el modo de gobernarse hombres, ciudades o estados; pero, no aceptemos consignas sobre el modo en el que nosotros debemos actuar personalmente. Curioso consejo éste, que prácticamente aconseja no aceptar consejos: actuar de acuerdo con lo que no es más congenial, sin escuchar indicaciones que se refieran a nuestro modo de comportarnos.

Antes de terminar con la carta a Soderini, quisiera resaltar algunas cosas que Maquiavelo no dice en su carta, y que son tan o más significativas que aquellas que efectivamente dice. Precisemos estas cuestiones aunque sólo sea para dejar constancia (si bien es este un debate que merece un trabajo pormenorizado y sistemático), de nuestro disenso personal con aquellos autores que recientemente han tratado de reinterpretar la cosmología y la antropología Maquiavelianas en consonancia con el pensamiento cristiano ${ }^{18}$. En primer lugar, en los Ghiribizzi, no se menciona a Dios ni a la providencia ${ }^{19}$. garantes

18 Pienso sobre todo en Sebastian de Grazia, cuya biografia sobre Maquiavelo resalta los elementos cristianos del pensamiento florentino (De Grazia, S., Machiavelli in Hell, New York 1989). También más recientemente por ejemplo en C. Nedeerman: "Fortune, God and Free Will in Machiavelli's Thought», (2000): Journal of History of Ideas, 60 (4), 617-638. Nosotros nos decantamos más bien por incidir en las diferencias entre Maquiavelo y la Weltanschauung cristiana en la línea, por ejemplo, de Münkler para quien la concepción de la historia maquiavelina margina toda dimensión transcendente y divina, cf. por ejemplo Münkler, op. cit., p. 243-4.

19 Desde un punto de vista general, en torno a la fortuna tanto para San Agustín como para Boecio, el mundo terrenal se caracteriza por el predominio de la fortuna y por la continua inestabilidad. En San Agustín, la estrategia contra la fortuna implica un abandono de los intereses corporales y la conquista de la salvación del alma en la civitas dei. El caso de Boecio es sin duda más complejo (ni siquiera está del todo claro si su Consolatio esté escrita desde una perspectiva cristiana), pero es obvio que frente a la temporalidad e inestabilidad de lo terrenal opta por la búsqueda de la eternidad y estabilidad a través de la contemplación filosófica y las virtudes espirituales. Con todo, Boecio defiende el valor intrínseco de las virtudes prácticas a las cuales el hombre no puede sustraerse. Sea como fuere, de una función desvalorizadora de lo terrenal no se halla ni rastro en Maquiavelo. En el esquema boeciano-tomista (hacemos, por supuesto, abstracción de sus diferencias), Dios regula el universo a través de la providencia y el destino: la providencia es la visión del universo considerando el punto de vista de su primera causa 
ineludibles de un concepto de fortuna compatible con el Dios cristiano. En segundo lugar, no se menciona en ningún momento ni la razón, ni el libre albedrío, ni la gracia, garantes también, según la doctrina cristiana de la libertad humana y del universo moral en el hombre.

El hombre parece estar dotado sólo de animo (carácter), ingegno (talento e ingenio) y fantasia (imaginación). En principio, habremos de admitir que el texto de los Ghiribizzi parece estar más cerca del determinismo naturalista ${ }^{20}$, común entre algunos averroístas escolásticos del Renacimiento como Pomponazzi, que de la tradición cristiana o humanista ciceroniana en la que, aunque por diferentes razones, la libertad humana, y la potencial determinación de la voluntad por la razón, aparecen siempre como una premisa no negociable. Aquí no podemos menos que estar de acuerdo con Parel, quien señala la importancia de la ausencia de las nociones de gracia y razón en el texto maquiaveliano ${ }^{21}$ (es curioso, por lo demás, que casi ningún autor haya subrayado que la virtud es la gran ausente de los Ghiribizzi). Con todo disentimos con Parel sea porque este autor presenta como "influencia astrológica» lo que

y descendiendo hasta el mundo físico. El fatum es el orden racional del mundo físico, mientras que la fortuna, es sólo ese mismo fatum en cuanto que desconocido por el hombre. A nada de esto se alude en el texto maquiaveliano. Parel habla en este sentido de Maquiavelo como manteniendo una posición «libertina" (cf. Parel, 1992, p. 58) En torno a la orientación conscientemente "laica y mundana" de los Ghiribizzi, Sasso, op cit., 1993, p. 238; y sobre las diferencias entre el esquema cristiano Dios-providencia-fortuna y el esquema Maquiaveliano, aunque antiguo, no deja de ser útil el trabajo de Cioffari, V, The Function of Fortune in Dante, Boccaccio and Machiavelli, Italica (1947), 24 (1), pp. 1-13, aquí p. 13 et passim.) Por último, también Leeker subraya que la principal función de la fortuna en el pensamiento cristiano medieval, de Boecio a Boccaccio, la de tener siempre presente la inestabilidad y la vacuidad de todo lo terreno (Leeker, op. cit., p. 414)

20 Es indudable que la noción de imaginación renacentista se concibe, incluso en el caso de los más férreos enemigos de la astrología adivinatoria, como determinada por la complexión de los humores corporales, los elementos y, en último término, por el movimiento de los cielos. Sería absurdo pensar que Maquiavelo negase la relación causal entre el movimiento astral y el movimiento humoral del hombre. Sin embargo, nada en concreto establece Maquiavelo sobre la particular influencia que los astros tienen sobre el hombre, ni sobre las posibilidades de una ciencia de estas influencias que pudiera dar algún fruto en el ámbito de la política. Pocock ha señalado que la concepción de la imaginación en los Ghiribizzi, tendría como antecedentes el tratamiento boeciano (que Maquiavelo usará en su Capitolo), a la vez que el mito de la caverna platónica (Pocock, op. cit., pp. 38-39).

21 "Machiavelli's anthropology does not have room for reason, intellect or grace [...] Machiavellian virtù is deprived of the benefits of rational insights that come form 'right reason' (recta ratio, ortho logos)." (Parel, op. cit., p. 91) 
en realidad es una crítica de la ciencia astrológica, sea porque tampoco hay una absoluta negación de la razón en el texto maquiaveliano: en efecto, una cierta "prudencia» (razón práctica) aparece reivindicada por Maquiavelo. Así, si bien los hombres normalmente actúan de acuerdo con su imaginación, Soderini sería una excepción: "...por lo que yo creo, no basándome en vuestro ejemplo, donde no se ve sino prudencia, sino en aquel de los más." $(G, 241)$. Por supuesto, aunque estemos ante un obvio caso de cortesía retórica, es indicativo que el entonces Secretario florentino, ya desde 1506, parezca aceptar la posibilidad de una oposición entre imaginación y prudencia.

\section{El Capitolo di Fortuna a G. B. Soderini}

Repasaremos ahora sucintamente lo que nos ofrece el poema conocido como Capitolo di Fortuna. Los versos adoptan un estilo mitológico, propio del género. La Fortuna aparece como una diosa dominadora del orden del tiempo, del que dicta su fluctuación y variación. El palacio de la Fortuna contiene las ruedas que hacen girar y cambiar las cosas del mundo. Evidentemente la Fortuna es aquí metáfora de la inestabilidad esencial por la que se hayan amenazados los logros y los proyectos de los hombres, tanto individuales como colectivos. Aparte de la boeciana metáfora de la rueda, se expone una nueva metáfora que se repetirá en $I l$ principe. la del torrente violento que, desbordándose, arrastra consigo todo lo que encuentra a su paso.

En cuanto al origen de la Fortuna, Maquiavelo asegura que non si sà ( $C F$, 44). Hago notar la distancia entre esta postura maquiaveliana y la cosmología cristiana; este 'no se sabe' de dónde procede la potencia de la fortuna significa prescindir de la providencialidad cristiana, destinada a neutralizar la aparente irracionalidad y amoralidad que el azar y lo fortuito introducen en el mundo. De hecho, de acuerdo con Maquiavelo, la Fortuna gobierna, no por delegación de la mente divina (como, pongamos por caso, en Dante) sino gracias a su «natural potencia» $(C F, 13)$.

Siguiendo con nuestra descripción, el caso y la suerte presiden ambos lados de la puerta del palacio de la Fortuna. Estas dos entidades son ciegas y sordas, lo que aparentemente nos distancia de un entramado cósmico moral o teleológico. También es notable el hecho de que la fortuna venga concebida determinada por el caso y la suerte, esto es, que sea hija de la contingencia, más bien que (por no hablar ya de providencia transcendente) de un inexorable fatum. 
Respecto al riscontro de los hombres con la fortuna, vuelve otra vez Maquiavelo a diferenciar entre los hombres a título individual y los colectivos, las ciudades o estados. Ausente en la carta a Soderini, aparece aquí por fin la virtud como reino contrapuesto al de la fortuna.

Respecto de los individuos, se insiste en lo ya dicho en los Ghiribizzi. Maquiavelo, en efecto, vuelve a hacer depender el éxito humano del acomodarse a los tiempos y del saber adaptarse al movimiento de las ruedas de la fortuna $(C F, 100-105)$. Se alcanza el éxito cuando nuestro modo de proceder concuerda con los tiempos, pero como la rueda de la fortuna cambia de dirección y dice Maquiavelo, "no pudiendo tú cambiar tu carácter [persona], ni abandonar la forma [l'ordin] de la que el cielo te dotoo $(C F, 110-114)$, la suerte nos abandona. Precisamente esta posibilidad de "cambiar de temperamento [persona]" nos está negado por cierta "virtud oculta que nos gobierna».

He aquí un elemento de fuerte carga naturalista y fatalística en la obra maquiaveliana. Porque, en efecto, una virtud oculta en el cielo que gobierna a los hombres, imprimiéndoles su carácter a través de una mezcla de humores (o a las ciudades) es justo uno de los supuestos básicos del determinismo astrologico: en el poema ya se nos había avisado anteriormente de que tú, en cuanto hombre, actúas según "que te hacen operar los humores" $(C F, 103){ }^{22}$. Ahora bien, frente a cualquier fatalismo de carácter providencial o teleológico, se impone una fortuna ajena a todo rasgo inteligente o intencional.

Además, Maquiavelo vuelve a buscar atenuantes a este fuerte naturalismo, por un lado, oponiendo por primera vez la virtud a la Fortuna: «Su natural potencia doblega a todo hombre; / su reino es siempre violento / si una excelente virtud no la desarma." (CF, 14-15); y por otro lado, porque parece volver a aceptarse que tendríamos mejor suerte si nos acomodamos a su variar, en la medida de lo posible ( $C F, 121-126)$. Por tanto, en último término, la invariabilidad de la naturaleza humana y el determinismo naturalista, parece que vuelven a ponerse entre paréntesis. No olvidemos, sin embargo, que queda sin resolver en qué modo esa "virtud", se pueda oponer a la fortuna, ni cómo pueda compaginarse la aparente rigidez de la naturaleza humana $(C F, 110-$ 114) con ese cambio deseable "en la medida de lo posible».

22 Y más adelante encontramos también una frase cargada de evocaciones nuevamente astrológicas: prender tu stella $(C F, 124)$. 
Por último, respecto de las ciudades y los estados, diremos que la Fortuna es, de nuevo, la fuente de ese cíclico alternarse de tiempos de tranquilidad y tiempos de guerra, abundancia y escasez y que produce en las ciudades situaciones en las que domina bien el ozio (causa de su corrupción), bien la necessità (causa de vigorización). Tal y como ya se apuntaba en los Ghiribizzi, los estados, para evitar la corrupción, están obligados a alternar una política de guerra y disciplina (personalizada en Rómulo), y una política de religión y humanidad (representada por Numa). Siendo esto una cosa nada fácil, sucede que las ciudades, los imperios, pasan de la gloria a la decadencia (o al revés), perdiendo su autonomía y dejando su suerte en manos de la Fortuna (es decir, en este caso, en manos de otros estados en ciclo ascendente).

El Capítulo XXV de $I l$ principe. La novedad Maquiaveliana

Lo primero en llamar nuestra atención en el capítulo XXV de $I l$ principe es la propia aceptación de Maquiavelo sobre su cambio de postura ante el problema de la fortuna. Afirma el florentino que es común a muchos hombres de su tiempo, y debido sobre todo a los rápidos y sorprendentes cambios políticos que se han producido en Italia, que "las cosas del mundo estén gobernadas por Dios y la fortuna, que los hombres no puedan corregirlas con su prudencia, es más, que no dispongan de remedio alguno...". De hecho, el florentino admite que él mismo se ha inclinado en el pasado a pensar, al menos en parte, en esta dirección ${ }^{23}$ (una autoreferencia que parece remitirnos a las dudas que asaltaban a nuestro autor en los Ghiribizzi y el Capitolo).

Se trata pues, al menos aparentemente, de cerrar el paso a la tentación fatalística. Pero ¿en qué modo? Algo que nos podría hacer sospechar la dirección del cambio es la introducción del dúo reinante "fortuna y Dios", cuando tanto en el Capitolo como en los Ghiribizzi la fortuna aparecía reinando en solitario. Además, esta novedad parece convenir con algo que nuestro autor dirá a continuación. El texto parece esgrimir y prácticamente proclamar una tesis clásicamente cristiana: frente a quienes creen (entre los que, como acabamos de ver,

23 "Esta opinión se he extendio en nuestros tiempos por la gran fluctuación de las cosas que se ban visto, y se siguen viendo hoy en dia, fuera de toda humana conjetura. Y pensdindo yo alguna vez en esto, me he inclinado, al menos en parte, a pensar esto mismo." (PXXV) 
parece ser que él mismo se hallaba), que todo está en manos de la fortuna (o Dios), Maquiavelo afirma que no todo: la mitad dependería del libre albedrío:

Sin embargo, a fin de que nuestro libre arbitrio no sea cancelado, puede ser cierto que la fortuna sea árbitra de la mitad de nuestras acciones, pero que igualmente ella nos deje gobernar más o menos la otra mitad a nosotros. $(P X X V I)^{24}$.

¿Está pues Maquiavelo cambiando enteramente su cosmología y antropología y emparentando su concepto de mundo y hombre con el de la tradición cristiana? Nuestra pregunta es, por supuesto, retórica. Cualquier lector que haya entrado un poco en el texto maquiaveliano advierte las dificultades implicadas en esta interpretación (que no obstante no ha sido suficiente para doblegar la audacia interpretativa de ciertos historiadores de las ideas). La doctrina cristiana (permítasenos simplificar las características más generales de su versión más divulgada y aceptada), aceptando las determinaciones naturales ( $\mathrm{y}$, en último término, astrológicas) sobre los apetitos, la sensibilidad y la imaginación humanas, insiste en la posibilidad de una activa indifferentia ( $y$, por tanto, de actuar siempre de acuerdo con la razón), y entiende como libre arbitrio la capacidad de la voluntad y la razón para elegir, con la ayuda de la gracia, entre el mal y el bien (en su versión agustino-voluntarista) o entre los medios para alcanzar un determinado fin (en su versión tomístico-intelectualista) ${ }^{25}$. Por lo demás, aclaremos antes de nada que es difícil imaginar siquiera a un Maquiavelo ignorante de la noción cristiana de libre albedrío, al menos en su sentido más genérico. Ni su formación cultural, ni otros escritos suyos (por ejemplo la Esortazione a la Penitenzia), permiten aventurar seriamente esta hipótesis. Pues bien, veamos si se defiende aquí una posición que podamos equiparar a las mencionadas.

24 Por lo demás, algo parecido se repite en la exhortación del último capítulo de $I l$ principe. "Todo concurre a favor de vuestra grandeza. Lo que falta, toca hacerlo a vos: Dios no quiere hacerlo todo, por no privarnos del libre arbitrio y la parte de gloria que nos corresponden. ( $P \mathrm{XXVI)}$ Destaquemos también el grado de ambigüedad que parece implicar el "puede ser cierto".

25 Para S. Agustín se trata de una facultad de la razón y de la voluntad por medio de la cual es elegido el bien, mediante el auxilio de la gracia, o el mal, (doctrina que parece desprenderse de su De lib. arb.; y sobre todo de De gratia et lib. arb.) Para Santo Tomás en el libre albedrío concurren elementos cognoscitivos y apetitivos, y sería un aspecto diferenciable, aunque no separable, de la voluntad (véase, por ejemplo, St. Tomás, Summa, I, 83, y sobre todo el artículo 4). 
Pero antes es necesaria una observación previa. En el capítulo XXV de $I l$ principe nuevamente nos volvemos a encontrar con la diferenciación entre la fortuna in universale y la fortuna in particulare ${ }^{26}$, una diferencia que, como ya insinuamos, cuando no viene identificada, provoca irreparables malentendidos, incluso entre los más sofisticados interpretes de Maquiavelo ${ }^{27}$. Como ya hemos visto es ésta la diferencia entre la fortuna que afecta a países, colectivos $\mathrm{y}$ ciudades y aquella que afecta a individuos.

Vayamos pues al particular, esto es, en terminología maquiaveliana, al hombre en cuanto individuo. Una vez más, el escritor florentino vuelve a presentar la cuestión a partir de la paradoja según la cual los hombres, sin que cambien en nada de modo de proceder, unas veces tienen éxito, otras veces fracasan. Y se repite también la idea de que, puesto que la fortuna es la responsable del cambio y continuo fluctuar de las circunstancias, quien fuera capaz de adaptarse a esta fluctuación conseguiría tener siempre buena fortuna. Ahora bien, vuelve a decir Maquiavelo, no se encuentra hombre tan prudente que sea capaz de tal comportamiento. ¿Por qué? Por algo que ya nos es familiar: porque los hombres, individualmente, no pueden desviarse de aquello a lo que les inclina la naturaleza, y en segundo lugar, porque los hombres con facilidad se persuaden de que aquello que funcionó en el pasado seguirá funcionando indefinidamente: la imaginación, reforzada por el estímulo del éxito pretérito,

26 De acuerdo con Parel esta diferenciación tendría una base astrológica en sentido fuerte (cf. PAREL, 1992, 70). Me parece, sin embargo, que el amplio manejo de la distinción en sentido más bien epistemológico (diferenciación de sujetos de conocimiento y acción: individuo, familia, ciudad), no implica la existencia ontológica, como parece sugerir Parel, de diferentes tipos de "fortuna", entre otras cosas porque la fortuna es, para Maquiavelo, más bien una relación dinámica que una entidad realmente existente, como lo fue para Dante. Incidentalmente, por ejemplo, he encontrado la misma diferenciación en Petrarca (Petrarca, Familiarem Rerum XVII, 3), quien por cierto era totalmente contrario a la astrología adivinatoria.

27 Por sólo citar dos casos importantes, en mi opinión es éste el principal punto débil de la sofisticada interpretación de Sasso (ver op. cit. 1993, 428-438), así como de la valiosa interpretación de M. VATTER: Between Form and Event: Machiavelli's Theory of Political Freeom, Boston 2000, pp. 185 y sgg. Este defecto lo hallo también en aquellos trabajos que han versado específicamente en torno a la cuestión de la fortuna en Maquiavelo, caso de los artículos ya citados de FlanAGAN, y de LeEKER, así como el de A. FonTANA: Fortune et décision chez Machiavel, "Archives de Philosophie", (1999) 62 (2), pp. 255-268.

28 "Ni se halla un hombre tan prudente que sepa acomodarse a esto: sea porque no se puede desviar de aquello a lo que le inclina la naturaleza, sea porque habiendo siempre prosperado caminando por una determinada vía, no puede persuadirse de que sea adecuado desviarse de ella." $(P X X V)$ 
se impermeabiliza a la función crítica de la prudencia ${ }^{28}$. Ahora bien ¿qué tiene que ver todo esto con el libre albedrío que anteriormente parecía haber defendido Maquiavelo? La voluntad guiada por la razón no aparece por ningún lado; no vemos tampoco la posibilidad de elegir entre el bien y el mal (que, por lo demás, no son siquiera mencionados), ni aparece mencionada virtud intelectual o teológica alguna. Sencillamente, Maquiavelo no está hablando de libre albedrío en sentido psicológico, sino de mera libertad mundana, esto es, la capacidad del hombre para determinar su suerte. Y lo único que en realidad ofrece Maquiavelo contra la fortuna, esto es, contra las determinaciones exteriores e interiores, nada tiene que ver con la Weltanschauung cristiana: la fortuna es mujer, amiga de los jóvenes y tímida ante la audacia; por ello, queriéndola someter, es mejor ser impetuoso y violento ${ }^{29}$ que actuar con demasiada cautela o respeto. En definitiva, no existe aquí, y no han faltado autores que lo subrayasen ${ }^{30}$, traza de libre albedrío en sentido cristiano. En realidad, aquello a lo que Maquiavelo llama libre albedrío no es más que la esfera de la acción humana, de su autonomía, sea colectiva que individual, y no el concepto divulgado en la psicología cristiana tradicional. La libertad individual que Maquiavelo defiende es la capacidad de actuar de acuerdo a nuestro temperamento, apetitos y pasiones con la mayor determinación y prudencia posible, para imponer nuestra voluntad sobre la fortuna o, al menos, para defen-

29 Un precedente del "comportarse violenta y valerosamente" ante la fortuna, puede verse en Bembo que habla de un «arrollar valerosamente a la enemiga fortuna": "Percid che ad uomo nelle lettere infin da fanciullo assai profittevolmente essercitato, si come egli è, più si conviene calpestando valorosamente la nimica fortuna ridersi e beffarsi de' suoi giuochi, che, lasciandosi sottoporre a lei." (Asolani, 2, II)

30 En este caso estamos de acuerdo con Parel, para quien Maquiavelo usa el concepto de libre albedrío de un modo puramente retórico (cf. PAREL, 1992, pp. 81- 82). También otros autores, como G. Inglese y J. Leeker, niegan el carácter técnico y cristiano de esta noción de libre albedrío: (cf. G. INGLESE, op. cit., 1995, nota 4, p. 162; mientras que Leeker [art. cit., pp. 4257] parece aproximar el concepto de libre albedrío al de ambizione.). También Cioffari señala que la noción de libre arbitrio implicada en este último pasaje nada tiene que ver con la concepción medieval (Cioffari, art. cit., p. 9). Por lo demás, creo que aquí se halla el epicentro antropológico de eso que Fontana describe como una voluntad autónoma de la transcendencia agustiniana, liberada de la lex y la ratio jurídica, de la teología y la moral cristianas (por no hablar del summum bonum neo-platónico) y que sitúa sobre el horizonte maquiaveliano el siempre peligroso riesgo de la tiranía (Fontana, art. cit., p. 266). En cualquier caso, el hombre maquiaveliano, libre de frenos externos e internos (miedo/esperanza) parece abocado al peligro de sus propios impulsos depredadores. En otro orden de cosas, Inglese en su nota al texto advierte que el capítulo aparece imbuido de un cierto tono providencialístico que, para ser sincero, a mí se me escapa. 
dernos de su poder. Por lo que se refiere a la mención de Dios al principio del parágrafo, recordaré simplemente que Maquiavelo a menudo yuxtapone en otras obras a Dios con la naturaleza (como en IF VI, 34; III, 13; VII, 21...), con los tiempos ( $I F \mathrm{~V}, 11$ y en el mismo $P \mathrm{XXV})$, o, como en el caso que nos ocupa, con la fortuna (también en IF VIII, 36), sin que por ello podamos, en absoluto, inferir la existencia una cosmología cristiana gobernada por un Dios providencialista. Por el contrario, estas yuxtaposiciones parecen teorizar un Deus sive fortuna sive natura más bien que la aceptación de una cosmología de tipo jerárquico.

Descartada la interpretación cristiana del "libre albedrío" en el contexto de la fortuna "particular", por lo que respecta a la fortuna "en universal", Maquiavelo adopta la metáfora del río o torrente desbordado, que saliéndose de sus márgenes acostumbrados, arrastra consigo las cosechas, los edificios, el orden humano. Pero a una inundación, dice Maquiavelo, el hombre la puede hacer frente construyendo diques, reforzando los márgenes del río, creando los presupuestos para canalizar la crecida. Pues bien, esto es lo que las ciudades, los colectivos, los "estados» pueden hacer para afrontar los golpes no previstos de la fortuna: proveer con prudencia, seguramente no para suprimir los desbordamientos, pero sí para mitigar sus efectos. En otras palabras: existe una virtud colectiva, que puede hacer frente a la fortuna, y que, se lamenta Maquiavelo, ha sido desplazada de Italia, encontrándose ahora en Francia y España y, especialmente, en la Magna (esto es, en las repúblicas suizas y alemanas). Ahora bien, en qué consiste esta virtud colectiva, Maquiavelo no lo trata en el capítulo XXV de Il principe (obviamente le interesa más bien aquí la virtud del príncipe) si bien sabemos en general cuáles son los medios con los que los estados pueden hacer frente a la adversidad: la prudencia de sus líderes políticos, buenas costumbres, buenas leyes (por ejemplo, en $D I, 11$ ) y, sobre todo, buenas armas (por ejemplo, en PXII) ${ }^{31}$. No está claro, por lo demás, si la virtud colectiva sea la propiedad de un ente real colectivo, de un sujeto autónomo y diferente de la suma de individuos, o nada más que la propiedad de

31 O citando a Parel: "milititary strength, a citizen army, sound diplomacy...» (Parel, op. cit., p. 69). Por lo demás, es obvio que el predominio de las armas (que en último término propende a cristalizar, no lo ocultemos, en una defensa del militarismo patriótico), la determinación y la fuerza, son elementos que conforman un cuadro con el que Maquiavelo se enfrenta a la cultura del ocio, de la pasividad, a la exaltación del padecimiento; en fin, al cuadro cultural heredado del cristianismo que, de acuerdo con el florentino, se halla en consonancia con un mundo basado en la servidumbre y que ha contribuido al caos y a la debilidad italiana. 
un agregado, una alianza. De cualquier modo, esta virtud es el equilibrio de las diferentes virtudes y prudencias particulares, en este caso dirigidas (al menos aquellas más decisivas) a reforzar o prolongar la prosperidad colectiva o el bien del estado.

Dicho todo esto, resta precisar en qué queda entonces el cambio de opinión del que Maquiavelo hacía gala al inicio del capítulo. Este cambio, a mi modo de ver, lo hallamos en la definitiva convicción de que se puede y se debe afrontar la fortuna, sea en el terreno individual, mediante una combinación de determinación, y audacia, sea en el terreno colectivo, mediante la prudencia: prudencia que se expresa en la fuerza de las armas y la introducción de buenas leyes y costumbres. Esto es, Maquiavelo parece querer enterrar definitivamente la tentación fatalista que deja todo en manos de Dios o los astros o de cualquier escepticismo que abogue por la resignación ante el poder de la fortuna. La historia y la política están parcialmente en manos del hombre, no cabe abandonarse a la suerte. Así pues, al menos en parte, el destino del hombre es (a semejanza del Dante del Canto XVI del Purgatorio) un asunto de su propia responsabilidad colectiva e individual. Esta idea que, aunque esbozada en los Ghiribizzi y el Capitolo, no conseguía llegar a definirse, en Il principe, aparece, en cambio, como ineludible certeza. Así, podríamos estipular que Maquiavelo se desmarca de dos tentaciones contrapuestas:

- la perspectiva fatalista que niega la posibilidad de la autodeterminación humana, o dicho de otro modo, de la libertad (no hablamos aquí de la libertad interior, sino de la exterior: la que en la tradición peripatética viene referida a los bienes externos).

- la perspectiva optimista que niega límite real alguno a las potencialidades de la virtud humana en la historia y la política; pero también de la perspectiva que proyecta la virtud como dirigida hacia un bien meramente interior y niega, por tanto, todo vínculo de ésta a los bienes exteriores y toda determinación por parte de temperamento o las pasiones.

Es aquí donde nuestra interpretación se desvía de aquellas que ven una contradicción y lucha interna en el texto y espíritu maquiaveliano, o de aquellas otras que conciben el texto como una teoría unívoca del poder de la fortuna. Interpretaciones que parten de un malentendido esencial: considerar que el capítulo XXV de Il principe aplica una idéntica teoría del riscontro a estados e indivi- 
duos, como si no fuera obvia la notable diferencia entre las condiciones en las que un sujeto colectivo debe operar: sea bien ordenado y en fase ascendente (i. e. república romana, o contemporáneo reino franco), o ya desordenado y en fase descendente (digamos Florencia); y las condiciones en las que un príncipe nuevo o un actor revolucionario (pongamos Cesar Borgia o Savonarola) o, en fin, cualquier actor político individual, debe actuar. Es esta resistencia a distinguir entre las dos esferas (aún cuando Maquiavelo advierte con notable precisión al lector de que la primera parte del texto versa sobre la fortuna in universale, la segunda, cosa muy distinta, de la fortuna in particulare), la que no permite ver que, para Maquiavelo, el único admirable chamaeleon que puede, no sólo prever la fortuna, sino también cambiar de persona para afrontar la variedad de los tiempos, no es ya Cesar Borgia ni Julio II, sino la Roma republicana. Otra cuestión es que incluso la prudencia y virtud de este animal colectivo, como veremos en la conclusión, este también, en último término, amenazada por serias limitaciones.

\section{El riscontro en los Discorsi}

En los capítulos VIII y IX de los Discorsi Maquiavelo vuelve a retomar en profundidad el tema de la fortuna y el riscontro. En el capítulo VIII se repite la teoría de la virtud individual:

... Los hombres en su proceder, y con mayor motivo en las grandes acciones, deben considerar los tiempos, y acomodarse a éstos. Y quienes, por mala elección o por inclinación natural, se disocian de los tiempos, viven, la mayoria de las veces, infelices, $y$ sus acciones obtienen un mal resultado, y lo contrario se dirá de aquellos que se concuerdan con los tiempos. (D III, 8)

En el capítulo 9, la fortuna vuelve a presentarse como el continuo fluctuar y variar de los tiempos. Nuevamente, además, se introduce ya en el título que encabeza el capítulo un elemento de confusión: éste reza "que conviene variar de acuerdo con los tiempos si se quiere tener siempre buena fortunas (D III, 9). Y sin embargo, en el interior del capítulo, se vuelve a exponer, a partir del ejemplo de Fabio Máximo, la inmutabilidad del temperamento: «Un hombre que se haya acostumbrado a proceder en un cierto modo, no cambia jamás.» (D III, 9) Más adelante aventuraremos una hipótesis que explique la razón de esta reiterada contradicción. 
A continuación se exponen las causas de esta imposibilidad para variar: primero, porque no podemos oponernos a lo que la naturaleza nos inclina; segundo, una vez más, por la obstinada persuasión de que nuestro comportamiento, habiendo sido eficaz en el pasado, lo ha de seguir siendo en el futuro ${ }^{32}$.

Vuelve Maquiavelo a distinguir entre individuos y colectivos. Respecto de los individuos asistimos a una repetición de lo dicho anteriormente, cambiando apenas el énfasis en la solución aportada al problema del riscontro: puesto que los hombres no pueden cambiar sus inclinaciones, tiene mejor suerte quién actúa según le constriñe la naturaleza (es probablemente superfluo volver a llamar la atención respecto de la total amoralidad y de la incompatibilidad de esta observación de actuar "según nos inclina nuestra naturaleza", con la noción cristiana del libre albedrío):

Pero aquel que viene a errar menos y tener más prospera fortuna es quién hace coincidir [riscontra], como he dicho, su modo de proceder con el tiempo, $y$ siempre procede seguin le fuerza la natura (D III, 9)

Respecto a la distinción entre individuos y colectivos, se lleva ahora el paralelismo bastante más lejos: en efecto, se nos dice que así como los individuos no son capaces de cambiar sus inclinaciones, parece que tampoco las ciudades son capaces de variar sus modos de proceder, y sus "órdenes" (en el sentido de sus leyes constitutivas e instituciones), en relación con sus propios 'tiempos'.

Pero el texto de los Discorsi introduce aquí un argumento pro-republicano. En efecto, las repúblicas afrontan con más garantías que las monarquías el variar de la fortuna, sencillamente porque las primeras, "por la diversidad de ciudadanos" que acceden al poder, pueden afrontar la necesidad inherente a cada momento con un tipo de hombre diferente, mientras que las monarquías (dependiendo solamente de la personalidad y talento de un único hombre), ven limitada seriamente su versatilidad.

32 "Y que nosotros no podamos cambiar, es a causa de dos cosas: la primera, que nosotros no nos podemos oponer a lo que nos inclina la naturaleza; la segunda, que habiendo uno prosperado bastante con un determinado modo de proceder, es imposible persuadirle de que pueda irle bien procediendo de otro modo: lo que causa que varie la fortuna de un hombre, porque ella varía los tiempos y aquél no varía los modos." (D III, 9) 
La originalidad Maquiaveliana, astrología, ciencia y modernidad

Como acabamos de ver, Maquiavelo sostiene que los hombres no pueden cambiar de proceder ni de modo de comportarse debido a su naturaleza. Ahora bien, hemos visto que el autor florentino parece también decir lo contrario: en el título del capítulo de sus Discorsi, afirmaba que los hombres «deberían cambiar y adecuar su modo de proceder de acuerdo con el cambio de los tiempos." ( $D$ III, 9) Además, en el mismo capítulo 9 del libro tercero de los Discorsi se nos dice que lo mejor es seguir las propias inclinaciones con determinación. Pero entonces, ¿se puede actuar en contra de nuestras propias inclinaciones? También en Il principe leemos que un príncipe debe tener un ánimo predispuesto a variar según los dictan «los vientos y las variaciones de la fortuna.» ( $P$ XVIII) Por último, en el poema sobre la Fortuna se menciona que la adaptación y el cambio es, dentro de ciertos límites, posible:

Pero si quiere uno apresar su estrella,

en lo que nos es posible, a cada paso,

hemos de acomodarnos al variar de aquella. $(C F, 978)^{33}$.

¿Existe una contradicción insalvable? Me inclino a pensar que la incoherencia es fruto en parte de las dudas que asaltan a nuestro autor, en parte fruto de su imprecisión conceptual. Una explicación puede intentarse atendiendo a un pasaje de su poema Dell'ambizione que ofrece una posible alternativa a estas contradicciones. El Capitolo dell'ambizione dedicado a L. Guicciardini es importante por diferentes razones, entre otras, porque Maquiavelo establece muy claramente que la inestabilidad de la fortuna no tiene tanto que ver con el movimiento de los astros como con el carácter de la naturaleza humana, dominada por la ambición y las pasiones de dominación. En efecto, se nos dice

33 "Pero se si vuol prender per sua stella, le quanto a noi è possibile, ogni ora / accomodarsi al variar di quella. (CF, 978) Por último, a modo de ejemplo externo a los textos más teóricos que nos han ocupado, en una carta a su amigo Vettori, de contenido ciertamente obsceno y humorístico, Maquiavelo afirma, entre bromas, que quien leyera su correspondencia quedaría maravillado con cuanta facilidad y rapidez pasan de lo serio a lo superficial, de lo grave a lo lascivo; a lo que el mismo Maquiavelo se responde que debe comprenderse que la naturaleza es varia, $y$ que quién la imita no puede ser censurado: "Questo modo di procedere, se a qualcuno pare sia vituperoso, a me pare laudabile, perché noi imitiamo la natura, che è varia; et chi imita quella non può essere ripreso." (Lettere, a F Vettori, 31-1-1515) Ver también Inglese, op. cit., 1984, p. 284. 
que a esto «instinto natural nos empuja». Todavía en un tiempo pre-cainítico se podía pensar en "hombres que vivían con simplicidad y desnudos / de toda fortuna, cuando todavia no existian / de pobreza y de riqueza ejemplos.» (CA, 52-4). Pero crecida "la mala simiente" y generalizada la ambición, la norma es que «uno desciende y otro sube; / de esto depende, sin ley o pacto, / el variar de todo estado mortal. (CA, 64-6).

Ahora bien, dice Maquiavelo, dado que la naturaleza humana se ve dominada por diferentes pasiones de posibles efectos dañinos (la ambición, la envidia, el odio), y puesto que el intelecto y la razón no pueden destruir estas pasiones, lo propio de un juicio y un intelecto sano, es acompañar la propia ambición con determinación y orden (esto es, con prudencia):

Ya que el hombre no puede expulsarla de si debe el juicio y el intelecto sano con orden y ferocidad acompañarla. (CA, 162-5)

Pues bien, si este texto es digno de la consideración que nosotros le concedemos parecería bastante claro cuál es la postura maquiaveliana sobre las pasiones e inclinaciones: la naturaleza humana, las pasiones, el temperamento, los afectos (convertidos en ambición, al fijar su ideal en un objeto externo) no pueden ser suprimidos por el intelecto. Uno puede oponérseles internamente, esto es, uno puede oponer una parte de su propia naturaleza a otra, unas pasiones a otras. Uno puede poner el intelecto y la voluntad al servicio de ciertos escrúpulos morales y en detrimento de las propias inclinaciones. Ahora bien, quien se opone sistemáticamente a la satisfacción de sus propias y más intimas inclinaciones, parece apuntar Maquiavelo, no está en su sano juicio, o en otras palabras, realiza un comportamiento inútil y auto-lesivo: inútil, aventuramos, porque tales inclinaciones, lejos de disolverse, le continuarán incitando y atormentando al tiempo que serán ineficaces respecto del orden de causas exteriores; auto-lesivo porque la no satisfacción de los humores e inclinaciones sólo puede conducir a un sentimiento de frustración, a un desequilibrio de naturaleza humoral. Por ello, y al menos si uno actúa con alguna esperanza de éxito o de satisfacción, el hombre debe siempre accompagnare su ambición, esto es, secundar el propio deseo con orden y determinación. Es este despliegue de prudencia que debe acompañar a nuestra naturaleza, lo que nos permite determinar el momento y el modo de proceder, de acuerdo con las circunstancias y con el temperamento de cada cual. Ya he 
citado un texto en el que Maquiavelo habla explícitamente de elección en oposición a inclinación natural: "Y quienes, por mala elección [cattiva elezione] o por inclinación natural, se disocian de los tiempos..." (D III, 8) No cabe duda de que es la prudencia la que nos enseña el modo y momento del variar, cuando la imaginación nos impulsa a seguir actuando de un mismo modo. Debido a esto, en la antropología maquiaveliana, si bien la prudencia puede oponerse a las inclinaciones naturales sólo relativamente, sí puede al menos limitar los peligros de la fantasía y propiciar así un mejor riscontro entre nuestro deseo y el mundo. En otras palabras, Maquiavelo no excluye como "psicológicamente imposible" que pueda uno cambiar de proceder o variar de comportamiento, sino que los márgenes en los que uno puede variar están ya determinados sea por los límites naturales relacionados con la capacidad intelectiva para comprender la oportunidad ${ }^{34}$ del cambio de proceder (una cuestión de naturaleza), sea por la capacidad y versatilidad anímica para cambiar de actitud (una cuestión de hábitos). La versatilidad es una cuestión de grado; la adaptación es posible, pero sólo hasta un cierto punto, sólo dentro de los límites de nuestra naturaleza y nuestros hábitos.

Además, la versatilidad no es suficiente cuando la fortuna domina totalmente el campo de acción, cuando la inestabilidad o la dificultad es tan grande que nos obliga a conocer y abordar la necesidad de cambios demasiado rápidos y radicales para ser adoptados. Pero además, esta versatilidad es limitada no sólo en sus márgenes sino en su repartición: la mayoría de los hombres ni conocen su necesidad, ni están en condiciones de actuarla. Por eso, Maquiavelo no se resiste a conformarse con tan pocos recursos que oponer a la fortuna y propone, particularmente en Il principe, otra alternativa, una alternativa, a la postre, extremadamente innovadora: si apenas es posible acomodarse a los tiempos, si no es posible estar al juego de la fortuna, invirtamos los términos: moldeemos nosotros los tiempos, golpeando con fiereza y audacia, tratemos de ser nosotros los que determinemos los tiempos y quizá la «fortuna adversa" de otros. Léase esa obra maestra que es La mandragola: audacia,

34 Como es bien sabido, la fortuna concede al hombre la occasione, estado de cosas favorable a la acción humana, aunque marcado por la transitoriedad ( D II, Prefacio; PVI; IFIV, 29). $\mathrm{G}$. Inglese expone que la occasione representa la retirada de la fortuna del escenario humano, que viene momentáneamente ocupado por entero por la prudencia humana: "...se 'occasione' e l'attimo prezioso in cui "senza rischi" può dispiegarsi la "prudenza" sta sola, e la Fortuna, che "si è ritratta», non ha dove applicarsi.» (Inglese, op. cit., 1984, p. 77) 
determinación y «astucia», que vendría a ser en Maquiavelo una modalidad de la prudencia activa, permiten conquistar el objeto de un deseo tan caprichoso como aparentemente inalcanzable.

Desde un punto de vista político, la teoría del riscontro que hallamos en $I l$ principe tiene una enorme originalidad: no es sólo, como ya dijimos, una incitación a la acción y a la determinación de la historia; es la certeza de que todo cambio revolucionario en política se lleva a cabo en condiciones de máxima incertidumbre: así, la incertidumbre se muestra en relación inversamente proporcional al valor político de la prudencia y la circunspección, y en relación directamente proporcional a la valía de la audacia y el arrojo. Dicho de otro modo: en la medida en que impera la inestabilidad y, por tanto, el «no saber," cabe abrirse paso con la audacia y el instinto.

La novedad maquiaveliana es aquí tan obvia, que cuesta creer cómo ha pasado tantas veces desapercibida: frente a la tradición Boeciana y estoica, frente a la tradición cristiano-aristotélica (aunque partiendo quizá, como explicaré a continuación, de una consideración de Aristóteles), que asume, para decirlo con Dante, que el hombre "cuanto más sujeto está al intelecto, menos sujeto está a la fortuna" (Conv. iv, 11) ${ }^{35}$, Maquiavelo, habiendo desconectando la cuestión de la fortuna del problema la integridad ética (perpetuado por los esquemas aristotélicos y boecianos que oponían interior-virtud a exterior-fortuna), tirando por la borda todo el cargamento moral que la cuestión de la fortuna llevaba consigo, se repropone el problema en el territorio de la política y la historia: territorios en los que la lucha con la fortuna se vierte hacia la exterioridad: se suprime pues la cuestión de una virtud interiorizada y ajena al devenir del mundo. La virtud individual maquiaveliana se desplaza irreversiblemente y exclusivamente hacia el efectivo curso de los eventos. Ahora bien, en la medida en que este curso se presenta como caótico o imprevisible,

35 Sobre la concepción de la Fortuna presentada por Dante en la Divina Commedia (Inf. VII, 25-99) son particularmente interesantes los comentarios de Cioffari, quien ve la especificidad dantesca en hacer asumir a la Fortuna una concreta función divina en clave cristiana (frente a Boecio o a Santo Tomás): la fortuna es ahora una "real" Inteligencia a la cual se le ha asignado, en buena lógica aristotélica, la distribución de los bienes externos «li ben vanì y «li splendor mondani, de las ciudades, las familias y los hombres. (Cioffari, art. cit., pp. 1-2). Por lo demás, sería superfluo señalar el abismo que separa la noción maquiaveliana de virtud respecto de la virtud entendida por la tradición aristotélico escolástica (véase por ejemplo Santo Tomás en Summa II-I, Q. 57, Art. 5). 
Maquiavelo se propone un giro inaudito: una doble transformación en virtud de la cual el intelecto se convierte en ancilla de las pasiones y de la ambición, y en el que la audacia y la determinación se eligen como las claves principales del modus operandi político. Entiéndase bien este punto: el papel de la «intuición», o la "inspiración» en la política había sido ya mencionada por Platón y Aristóteles ${ }^{36}$, y mucho más cercano al caso de nuestro autor, por Pontano ${ }^{37}$. Todos ellos destacan el caso del actor político afortunado o irracionalmente inspirado para actuar con éxito: en todos ellos existe un acercamiento de la actividad política a la actividad profética o poética. Pero la transformación maquiaveliana, me parece, consiste, primero, en acentuar el aspecto violento y atrevido de esta política carente de sostenimiento racional; y, en segundo lugar, consiste en transformar este fenómeno en el paradigma que rige las relaciones entre la fortuna y la virtud individual (y no simplemente de la acción política afortunada), al menos en determinadas condiciones. Es precisamente en esas condiciones (entre ellas, sin duda, las condiciones en las que se origina un príncipe nuevo), en donde una realidad política estable sólo puede construirse a base de osadía y ambición decidida, y en donde los titubeos y la circunspección parecen significar para Maquiavelo una actitud ineficaz o directamente dañina.

Dicho todo esto, no hallo en Maquiavelo una superación sintética de la concepción de la fortuna que otros han visto. De hecho, no me parece que exista en su obra una teoría unitaria del encuentro virtud/fortuna; la teoría maquiaveliana del riscontro viene atravesada por una casuística, interrelacionada y de límites ambiguos que se desbordan recíprocamente. Pero casuística insalvable, que se anuda fundamentalmente a partir del doble eje indivi-

36 En efecto, que yo sepa, nadie ha tomado en consideración que la versión maquiaveliana podría estar desarrollando una fórmula aristotélica de la Ética Eudaimonista (1247 b7), en la que se habla de una fortuna natural que se constituye por un impulso interno (Úrexis) e irracional (, logos); un instinto personal que guía al hombre hacia un deseado éxito en el momento oportuno, generalmente, en detrimento del sentido común (1247b37). En el caso de Aristóteles, se trataría en efecto de una especie de inspiración divina (1248a 26-b4) retrotraible quizá a la hipótesis provisional que cierra el Menón y que concibe la virtud del político no como un verdadero conocimiento, sino como "opinión verdadera" en nada diferente de la «inspiración" que guía a vates y adivinos (Menón, 99b-100c)

37 El caso de Giovanni Pontano es realmente característico y creo que no ha sido mencionado por ningún crítico en relación a este tema. En un pasaje de su De fortuna se halla bien tipificado un tipo de comportamiento sine ratione, y sine consilio movido por mero instinctus e impulsu: Pontani, De Fortuna, I, p. 280. 
dual/colectiva (por cuanto respecta al sujeto de la acción), y orden/desorden o sano/corrupto (por cuanto respecta a las condiciones de la materia y los tiempos sobre las que la acción se ejecuta). Lo cual no significa que no exista en absoluto una noción general de virtud en la obra maquiavelana: desde una perspectiva general y psicológica la virtud no es otra cosa que la capacidad humana de proyectar ${ }^{38}$ efectivamente los deseos y ambiciones (sirviéndonos de la prudencia ${ }^{39}$ o de la audacia); y, en su vertiente política, la virtud, no puede ser otra cosa que la capacidad (individual o colectiva) para influenciar y determinar ${ }^{40}$ el curso de los acontecimientos políticos e históricos de acuerdo con ciertos propósitos dados.

Queda por resolver también la cuestión de dónde se halle el límite de la virtud colectiva. De lo hasta ahora expuesto se colige que si la fortuna no fuera nada, y la virtud colectiva no tuviera más límite que su propia ausencia, un estado bien ordenado y en donde existiera gran cantidad y variedad de virtud, debiera en principio estar exento a los avatares de la fortuna: la política pudiera ser entonces un arte preciso y sería factible la construcción de una «repúbli-

38 La versión de virtud más genérica la hallamos quizás en Prezzolini que la ha caracterizada como un componente activo comparable a la d_namis griega (G. Prezzolini, Machiavelli Anticristo, Roma 1954, p. 28). Una atractiva fórmula de Pocock que se aproximaría a nuestra perspectiva es aquella en la que se describe la virtud como el principio formativo de la fortuna: la forma capaz de dar una figura a la fortuna-materia (Pocock, op. cit., pp. 40-41). En cualquier caso, sobre las diferentes acepciones del término virtud en el Renacimiento es útil el artículo de R. Price, The Senses of Virtù Reconsidered "Political Studies, 15 (1967), pp. 159-72. Hablamos de "capacidad" (que puede no llevarse a efecto) puesto que de otro modo no cabría hablar, como a menudo hace Maquiavelo, de una virtud a la que no se le presenta la ocasión para desplegarse (a este respecto, cf. Sasso, op. cit, 1993, pp. 410-12)

39 Esta prudencia maquiaveliana me parece igualmente enfrentada a la imaginación individual en sentido genérico y a la "imaginación académica o política" de los utópicos, o de quienes piensan en general que es factible una sociedad en la que los hombres ajusten libre o racionalmente sus comportamientos a los principios de la moral. Es ésta, en buena medida, la misma prudencia y talento que aparecen en la Mandragola y que se difundirán en la literatura picaresca del Renacimiento y el Barroco europeo. Maravall señaló en su momento que la picaresca fue uno de los medios de difusión del maquiavelismo popular cuando el maquiavelismo erudito era reprimido por la Reforma y la Contrarreforma. J. A. MARAVALL, Estudios de historia del pensamiento español: Serie tercera: Siglo XVII, Madrid 1975, p. 57 y 111.

40 Desde un punto de vista político, Maquiavelo parece admitir que la virtud política merecedora de mayor gloria es aquélla capaz de trazar una forma efectiva y duradera en el caos impuesto por la fortuna, y entre todas, aquella capaz de crear o renovar una forma política o religiosa (ver, por ejemplo, $D I, 10$ ). Esto no quita para que su rigor y coherencia le permitan también discutir la condiciones y la virtud necesaria para destruir una república ( $D$ IIl, 7-8) 
ca perpetua" capaz de sobrevivir indefinidamente al efecto corruptor del tiempo y a las variaciones de la fortuna, que ya no le afectaría seriamente. Una república perpetua que Maquiavelo parece descartar en $D$ III, 17 para, a continuación, afirmar en $D$ III, 22.

En realidad, la contradicción es aparente: en $D$ III, 22 lo que Maquiavelo afirma es que una república podría ser perpetua si hubiera en ella hombres y leyes capaces de reordenarla periódicamente; mientras que aquello que niega en $D$ III, 17 es que pueda ordenarse desde el principio una república perpetua. Esto es, una república no puede constituirse como perpetua desde sus orígenes (el tiempo corrompe la materia de las repúblicas) ${ }^{41}$ pero puede, si se reordena periódicamente, perpetuarse. Ahora bien ¿de qué depende que una república se pueda reordenar periódicamente? Como Maquiavelo bien dice, depende en parte de que quienes la ordenaron lo hicieran disponiéndola a la versatilidad; pero también depende de que en tiempos de decadencia nazcan en ella hombres capaces de ir contra la tendencia de su tiempo para retrotraerla a sus principios cívicos. Es decir, en último término, una república, para ser perpetua, vuelve a necesitar de la fortuna, de que la contingencia le conceda el nacimiento de hombres con la virtud necesaria para llevar a cabo esta periódica reforma. Y poco o nada puede hacer aquí la educación (a la que Maquiavelo otorga, por lo demás, una enorme importancia); en este caso la virtud de estos hombres habrá de tener un carácter extraordinario, contra corriente, contra el signo de los tiempos. Es por ello, entonces, que también la virtud colectiva, en una dimensión temporal mucho más extensa, tiene unos límites impuestos por el reino de la contingencia ${ }^{42}$.

Para terminar, aprovecharemos la ocasión para decir algo sobre carácter moderno o premoderno del pensamiento maquiaveliano y, en particular, de su cosmología y antropología. De hecho, estas últimas han sido a menudo iden-

41 "Se necesita, si se quiere asumir poder en una república para introducir una forma nociva, hallar ya la materia desordenada por el tiempo y que, poco a poco, de generación en generación, se baya conducido hacia el desorden: y ella se conduce necesariamente si, como ya se razonó anteriormente, no se vigoriza con buenos ejemplos o con nuevas leyes que la reconduzcan a sus principios." $(D$ III, 8) El pasaje debe relacionarse con $D$ III, 1 donde la cuestión corrupción-renovación se aborda en profundidad.

42 Tampoco debiéramos olvidar que a la corrupción interna y a la amenaza de la virtud externa pueden ańadirse otros factores históricos (emigraciones e invasiones humanas) o naturales (periódicos cataclismos) que pueden destruir un determinado organismo político o incluso el conjunto del colectivo humano (ver a este propósito el famoso $D \mathrm{II}, 5$ ). 
tificadas como el talón de Aquiles del pensamiento del florentino. Horkheimer, por ejemplo, pensaba que el naturalismo psicológico era el límite y principal error del maquiavelismo. Así, la deficiencia mayor de la concepción maquiaveliana consistiría en atribuir a la naturaleza humana características que en realidad están social e históricamente construidas. El maquiavelismo, dirá Horkheimer, viene a ser en esto enteramente dogmático, porque atribuye a la estructura natural humana aquello que en realidad está mediado histórica y socialmente ${ }^{43}$. Si el defecto que Horkheimer encuentra en Maquiavelo, más allá de su naturalismo, es su desconfianza respecto de la capacidad de los individuos y las sociedades políticas de autodeterminarse infinitamente, estaremos de acuerdo. Nuestro autor acepta y afirma la existencia de fuerzas o tendencias naturales que parecen sustraerse al control de la praxis humana. Ahora bien, como ya hemos visto, tales fuerzas no son insuperables, ni irreversibles; no imponen un fatal destino a los cuerpos políticos, pues como hemos visto, su duración, su forma y su vigor, dependen en buena medida de la prudencia humana y la fortuna. Además, cualquiera que haya leído los análisis históricos de Maquiavelo comprende que esto es un marco puramente general, y que Maquiavelo rara vez acude a él para explicar el desarrollo de los procesos históricos. Analícese el ascenso y la caída de la república romana. El factor natural es imperceptible. Véase la historia y decadencia de Florencia: Maquiavelo, a diferencia de Dante, a diferencia de Savonarola y de tantos otros, no apela en ningún momento a ese lugar común del «carácter de los florentinos» ni a elemento natural alguno. Léase la explicación de la debilidad política de Italia, o de la fortaleza de Francia: el pensador florentino prescinde completamente de cualquier naturalismo psicológico. Claro que existe un naturalismo o, como Sasso nos ha enseñado, una batería de naturalismos, que componen un marco desde el que explicar las inclinaciones naturales de los sujetos políticos. Pero este naturalismo antropológico y cosmológico es sólo un factor dentro de un múltiple y heterogéneo concursus causarum que permite dar cuenta de ciertas tendencias históricas: por ejemplo, la tendencia hacia la corrupción cuando se considera un ciclo largo en un cuerpo político. La dico-

43 M. HORKHEIMER, Maquiavelo y la concepción psicológica de la historia, en "Historia, Metafísica y Escepticismo", trad. de M. Del Rosario Zurro, Madrid, 1982, pp. 42-43. Con más cautela que Horkheimer, Gramsci se refiere a esta oposición naturaleza humana / historia en relación a Maquiavelo, sin decantarse en una u otra dirección (A. GRAMSCI, Quaderni del Carcere, Turín, 1977 [1932-4], vol III, Q. 13 (XXX), pp. 1598-9). 
tomía virtud/fortuna, las posibilidades que ésta abre, rompe con la concepción política clásica y cristiana que situaban en la naturaleza o en Dios el elemento de absoluta necesidad y de absoluta legitimidad. Quizá ha sido M. Vatter quien mejor ha visto que, reubicando la historia y la política en un marco de contingencia o de "necesidad" modificable, el pensamiento maquiaveliano instaura algunos de los fantasmas típicos de la modernidad: la cuestión central libertad política y la praxis revolucionaria ${ }^{44}$.

Hemos ya dicho que la astrología, no forma parte de la descripción maquiaveliana para explicar las causas de lo procesos históricos o políticos. Sin embargo, se ha querido reintroducir la astrología en el pensamiento maquiaveliano estableciendo, por ejemplo, que la que fortuna sería algo así como una entidad cosmológica cercana a la noción ptolemaica de "voluntad del cielo" 45 . Creo que es evidente que este planteamiento mal casa con el pensamiento Maquiaveliano. Por supuesto que el Secretario florentino parece aceptar la influencia externa del alma humana por el cielo: éste forja el carácter, la disposición humoral ${ }^{46}$. Ahora bien, precisamente no veremos a Maquiavelo jamás proponer la astrología como

44 VATTER, op. cit., pp. 2, 7-9 et passim. En realidad la entera obra de Vatter está orientada a poner de manifiesto la ruptura maquiaveliana con el naturalismo clásico y el eticismo y transcendentalismo cristiano, inaugurando así tanto las posibilidades como los riesgos de la modernidad.

45 PAREL, op. cit., p. 64. Otro tópico recurrente en la cultura astrológica era noción ptolemaica es la del "punto de Fortuna", una medida astrológica a partir de la que, en teoría, se podía determinar la duración y cualidad de la vida de los individuos. (Ptolomeo, Tetrabiblos III, 10; III, 14). De la crítica Maquiaveliana al valor de la astrología adivinatoria hemos hablado en nuestra nota 15.

46 Si quisiéramos trazar un sintético cuadro del Renacimiento en este aspecto, señalaremos que algunos autores, siguiendo a Ptolomeo, proponen la total determinación del hombre por los astros y aceptan, no sin cierta prudencia, el valor de la astrología divinatoria (Pomponazzi o Pontano); otros, ateniéndose más fielmente al dogma cristiano, aceptan la astrología adivinatoria en la sensibilidad y el cuerpo humano ( $y$, en particular, su uso en medicina), pero le niegan toda jurisdicción en la parte espiritual del alma y el libre arbitrio (Ficino, Landino...). Otros, en fin, aunque acepten ciertos influjos generales de los astros, aceptan la astrología matemática (en realidad, lo que ya en la modernidad se ha venido a llamar astronomía), niegan cualquier posibilidad (cognoscitiva, moral y utilitaria) para la astrología adivinatoria y especulativa (Giovanni Pico della Mirandola, Savonarola). Me parece que con razón, T. Flanagan resalta que el concepto maquiaveliano de fortuna no tiene nada de astrológico, ni las "fuerzas ocultas" juegan papel alguno en su filosofía política (Flanagan, art. cit. p. 50); En este mismo sentido, también M. A. Granada niega el determinismo astrológico como componente de la política maquiaveliana, Granada, M. A., Cosmologia, religión y politica en el Renacimiento, Barcelona 1988, ver sobre todo las páginas 60-69. 
fuente de conocimiento político, cosa que por lo demás era bastante común en el Renacimiento y cuyo paradigma es sin duda Pontano ${ }^{47}$. Distanciamiento prudente o convencido agnosticismo racional, lo cierto es que Maquiavelo ignora $y$, como hemos tenido oportunidad de ver, rechaza explícitamente cualquier recurso a la astrología, sin que, desde luego, niegue por ello la relación genérica entre el continuo cambio de las cosas humanas y el movimiento y orden supralunar ${ }^{48}$. Ni tampoco nos parece justificado afirmar que Maquiavelo haga uso de un lenguaje astrológico técnico, en virtud del cual, por ejemplo, "los cielos" representarían lo necesario y el orden, y la fortuna vendría a ser equivalente a lo fortuito, el capricho de los cielos. Me temo que carecemos de pruebas textuales para asumir que una tal dicotomía entre lo fortuito y lo necesario tenga en su pensamiento un alcance ontológico. Ya apuntábamos al principio que la fortuna no es más que la parte del cosmos que afecta al mundo humano y que es imprevisible para el sujeto gnoseológico (individual o colectivo). Hemos visto también que para Maquiavelo la fortuna existe en cuanto $\operatorname{tych} A$ (ignorancia subjetiva de las causas); pero de sus textos yo al menos no colijo que quepa hablar de autom,ton en sentido ontológico (esto es, de objetiva accidentalidad e indeterminación de un efecto), como sí cabe hacerlo respecto de la cosmología de Aristóteles. Mas bien creo que hemos de admitir que nuestro autor, exento de compromisos precisos por lo que se refiere a la estructura de la naturaleza (al menos en este ámbito), se mueve en el terreno de la indefinición.

47 Así, refiriéndose a la invasión de Carlos VII: "Le invasioni longinque et senza precedenti iniurie, quale incurre, soleno intervenire per la vicinità quando uno prencipe confina con l'altro, proveneno da movimenti celesti, come designano per le Comete e per grande coinuctione de stelle, quale ¿ questa invasione al vostro Padre et ad voi facta (...)» Fr. Colangelo, Vita di Giacomo Sannazaro, Napoli, 1819, p. 185. Por lo demás, Pontano no se limita a citar causas celestes, sino también el componente ambiental y humano: "per ben che vostro Avo prima, e poi vostro Padre, se l'habbiano procurate per li avari et violenti loro portamenti; et cosi el ciel oadopera secondo la materia disposta, et quando il cielo non trova resistentia inferiore, tira le cose al curso suo, come fa di un fiume repentinamente ingrossato di piovia e d'acqua adventitie, quando non sia provisto alle ripe et ad le argini. La piovia vi è venuta addosso, et tale, che havete il maior Re del mondo addosso, l'impero e grandissimo, e tucta Italia le ha data via et habilità.» (Ibid.). Creo adivinar, y hasta donde yo sé ha pasado desapercibida a los exegetas maquiavelianos, una importante similitud entre esa inundación "de un río repentinamente engrosado" y la falta de prevención ante las inundaciones (la ausencia de "ripe" y "arginin) con el celebre pasaje de Il principe. Sobre la complejidad y riqueza del posicionamiento pontaniano (y su contraposición al converso Pico) utilísimo es el clásico de B. SolDATI, La poesia astrologica nel 400, Firenze 1986 [1905] , pp. 199-314.

48 Como señala al respecto por ejemplo G. Inglese, op. cit., 1984, p. 80. Ver también la nota 19 de nuestro artículo. 
Maquiavelo hace uso en sus escritos de topoi (que pueden rastrearse tanto en el mundo greco-latino como en el medievo cristiano o en el quattrocento humanista) ${ }^{49}$, aprovechándolos en función de sus intuiciones teóricas. Precisamente el hecho de que a menudo en sus textos intercambie fortuna, suerte, tiempos, naturaleza o Dios es ya índice del carácter vago de su planteamiento, casi siempre ajeno a los tecnicismos astrológicos. Inútil, por tanto, nos parece el tratar de descubrir en éstos un rigor teórico donde precisamente Maquiavelo se sitúa conscientemente en una prudente generalidad. Inútil, también, buscar en este campo un examen filosófico especializado: baste pensar en este sentido en los sofisticados análisis aristotélicos, boecianos o tomistas, para apreciar el abismo que separa a éstos de la aproximación a la cuestión por parte del florentino. El hecho es que Maquiavelo asume, casi sin discusión, aquellos posicionamientos que le permiten fundamentar sus intuiciones políticas y antropológicas. En definitiva, mal se puede defender el «astrologismo" de quien, como hemos visto, invalida una y otra vez, el valor de la astrología en la política. Y mal se puede afirmar que la fortuna maquiaveliana sea una fatal "voluntad del cielo," necesaria o arbitraria, cuando, por lo que respecta al campo de la acción individual, se nos conmina una y otra vez a actuar y golpear a la fortuna, a ocupar, en la medi-

49 Por ejemplo, Leeker señala que, abstrayéndonos de los componentes originales, la concepción maquiaveliana adopta elementos del mundo clásico (por ejemplo, la fortuna como la dispensadora [Lienferantin] de la ocasión); elementos del mundo cristiano (sobre todo, en sus primeros escritos, el caso de las alegorías referidas a la rueda, su representación como la diosa maligna o su morada en forma de palacio); y por último, de la literatura humanista como oposición entre virtud y fortuna en favor de la virtud (aunque como resistencia); y más específicamente el enfrentamiento a la fortuna a través de la actividad y laboriosidad (cf. LEEKER, art. cit., 429). Respecto del humanismo y su nueva concepción de la virtud in actionibus, pero con todo, diferente del cuadro maquiaveliano, véase el citado artículo de Paparelli, pp. 82 et passim. Por el contrario, por ejemplo $\mathrm{N}$. Wood, parece no distinguir la virtud maquiaveliana de la humanista: N. WOOD, "Machiavelli's humanism of action", en The Political Calculus, Parel et alli, Toronto 1992, pp. 33-57 aquí p. 56. En oposición a Wood (y sobre todo a Q. Skinner), ha sido seguramente W. R NEWELL, quien más énfasis ha puesto en resaltar la novedad maquiaveliana (una virtud activa moldeadora del mundo, una fortuna entendida como modificable) respecto de la visión humanista (y no digamos de las posiciones agustinistas). Según Newell, la mayoría de los humanistas consideran el cosmos (y por ende, la historia) como una realidad perfectamente racional y por lo tanto, no modificable, una concepción básicamente extraña al pensamiento maquiaveliano. Compartimos la idea de fondo de Newell (en realidad no incompatible con las de Leeker), aunque disentimos sea en ciertos detalles de su distinción, y en los cuales no podemos entrar aquí, sea en su interpretación de ciertos humanistas (cf. NEWELL, W. R., aquí pp. 614 y 628-9). 
da de lo posible, su lugar con nuestras acciones, a ser nosotros, y no ella, quienes esculpamos el perfil de la historia ${ }^{50}$.

Claro que algunos pasajes maquiavelianos arrojan una noción de fortuna diferente a la aristotélica y que, aunque diferente también a la ptolemaica, parece más cercana al fatalismo apuntado por Parel. Con todo, en mi opinión, en estos casos podría decirse, como ya señalamos, que Maquiavelo identifica la fortuna con la naturaleza en general, o incluso con la necesidad, más que con la tych $\hat{A}$ aristotélica o astrológica ${ }^{51}$.

$\mathrm{Si}$ atendemos al núcleo teórico del cuadro maquiaveliano parece que el dominio de la fortuna no está en las lejanas estrellas, sino, por un lado, en la propia naturaleza humana y estructura del mundo (en el que el hombre apa-

so Todos las apreciaciones esgrimidas por Maquiavelo para entender el curso de la historia y enfrentarse a lo fortuito pertenecen al ámbito de la historia natural o son estrictamente socio-políticas. Frente a la contingencia, no existe, ya lo hemos visto, una ciencia cuyos cálculos astrológicos prediga los acontecimientos: sino sólo ingenio y audacia para la empresas individuales; buenas armas, buenas leyes y adecuada educación (religión) para garantizar la solidez de ciudades y reinos. La política, repito, no prevé en el florentino, a diferencia de muchos de sus contemporáneos, recursos relacionados con la astrología judiciaria (lo que tampoco quiere decir, como bien sabemos por D I, 56, que Maquiavelo niegue la existencia de la adivinación simpliciter). ¿Qué fatalismo cabe en quien, por lo que se refiere a los sujetos colectivos, afirma una y otra vez el valor de la virtud frente a la fortuna? En un ejemplo que nos parece poco discutible, ante el debate de si los romanos debieron su ascensión más a la fortuna o a la virtud, Maquiavelo no duda en afirmar que "...la fortuna que tuvieron los romanos, la tendrian cualesquiera principes que procediesen como los romanos, y poseyesen su misma virtud" ( $D$ II, 1)

51 Así, en el capítulo XXV de Il principe "Sin embargo, para que nuestro libre arbitrio no sea cancelado, juzgo que puede ser cierto que la fortuna sea juez de la mitad de nuestras acciones, pero que también ella deja a nuestra tutela más o menos la otra mitad." ( $P \mathrm{XXV})$ Reparemos en la inquietante responsabilidad atribuida por Maquiavelo a la fortuna. No es que nosotros seamos los dueños de la mitad de nuestras acciones, sino que la fortuna nos deja, nos concede, este don de ser responsables de una parte del resultado de nuestras acciones. También en un capítulo de los Discorsi, se nos dice que "La fortuna ciega los ánimos de los hombres, cuando ella no quiere que estos se opongan a sus planes." (D II, 29) Y nuevamente algo parecido encontramos en su Vita di Castruccio, en donde se hace a la fortuna responsable de las determinaciones sociales (negativas o positivas), que el hombre encuentra al nacer: "Creo que esto nazca de que, queriendo la fortuna demostrar al mundo que es ella, y no la prudencia, la que hace a los hombres grandes, empieza ya a demostrarnos sus fuerzas ya desde el momento del nacimiento, de modo que la prudencia no pueda jugar ningún papel." $(V C, 107)$ "Pero la fortuna, que quiere ser la juez de todas las cosas humanas, no me ha concedido tanto juicio como para conocerla con antelación, ni el tiempo suficiente para poder superarla." $(V C, 129)$. En todos estos casos me parece que la fortuna Maquiaveliana parece acercarse a un concepto de fortuna global, que recoge tanto la naturaleza como la contingencia histórica. 
rece como un ser con mucha más capacidad de desear que de obtener y en el que la ambición es siempre un elemento predominante $(D I, 37)^{52}$; por otro lado, en la lógica natural de la historia de los cuerpos políticos: todas las cosas humanas, llegadas a su máxima perfección, tienden a declinar y a corromperse, de aquí el cíclico variar y la inestabilidad (cf. $I F \mathrm{~V}, 1$ ). Esencial es este principio para entender algo del florentino: las cosas humanas se hallan en permanente e inarrestable movimiento ( $D I, 6 ; D I I$, pref.), lo que significa que de la estabilidad y seguridad, sólo se puede ir hacia la inestabilidad. En otras palabras, la fortuna debe su existencia a la estructura de la naturaleza humana (y básicamente, al conflicto generado por su insaciable ambición), y a la lógica que la naturaleza impone en la historia de los cuerpos políticos (de la perfección a la corrupción y viceversa) ${ }^{53}$.

Por todo lo dicho y aunque sea quizás entrar en una polémica esteril, no nos convence la idea de que el cuadro cosmológico de Maquiavelo sea básicamente "premoderno" y que su concepción de la historia y la política tenga un carácter arcaico y desfasado ${ }^{54}$, una idea que ha puesto de moda A. Parel y que

52 Creo que con acierto M. A. Granada ha subrayado la importancia de este poner en la ambición, este impulso a modificar el status quo, el origen de la inestabilidad de las cosas humanas y el predominio de la fortuna. (M. A. GRANADA, op. cit., pp. 226-227)

53 A menudo, esa contingencia, que muchas veces Maquiavelo designa con la palabra fortuna, es simplemente la virtud de los otros. Por ejemplo, G. Inglese, en mi opinión con razón, ha subrayado que la noción maquiaveliana de fortuna, al menos en ciertos momentos, puede ser interpretada como una metáfora de la relación histórica de los pueblos. (INGLESE, op. cit., 1984, p. 81). Un artículo dedicado específicamente a desentrañar los orígenes humanos de la fortuna es de O. BALABAN: The Human Origins of Fortuna in Machiavelli's Thought, "History of Political Thought", (1990), XI (1), pp. 20-36. Este autor subraya los orígenes humanos de la fortuna, pero disentimos en su reiterada oposición entre lo humano y lo natural, cuando es precisamente la naturaleza en general y la naturaleza de la cosas humanas, las responsables del dominio de la inestabilidad.

54 Cf. PAREL, op. cit., p. 160. Según el autor americano también el ataque maquiaveliano al cristianismo, basado, entre otras cosas, en la concepción circular y repetitiva de la historia, implicaría una cosmología pre-moderna (PAREL, op. cit., 156-7). Pero Parel aquí no distingue entre el determinismo naturalista que presenta la anacyclosis polibiana y el significativo papel de la contingencia (histórica) que se haya en la versión maquiaveliana $(D I, 2)$. Precisamente en la recepción polibiana (donde Parel parece concebir uno de los pecados antimodernos de Maquiavelo), Marramao ha venido a identificar el inicio de la modernidad. (cf. MARRAMAO G., Dopo il Leviatano. Individuo e comunitá nella filosofia politica, Torino 1995, p. 382-3). Algunos pasajes de Marramao en torno a la cuestión del progreso y a su relación sea con el esquema de la historia maquiaveliano sea con la escatología cristiana nos parecen más que discutibles. En este sentido, considero acertado el posicionamiento de M. A. Granada quien ve a un 
parece haber creado escuela ${ }^{55}$. Porque nos parece poco razonable plantear que el sistema maquiaveliano sea una especie de emanación de su cosmología, o que toda su teoría política se halle prisionera de una cosmología precopernicana: justamente, es la ausencia de un cuadro cosmológico riguroso lo que le permite a Maquiavelo utilizar las diferentes opciones cosmológicas para ir apuntalando sus intuiciones históricas y políticas; intuiciones cuyo principal nutrimiento procede, sin duda, de su talento teórico y de su propia experiencia política, así como, claro está, de sus lecturas; en ningún caso de un esquema cosmológico previo. Cierto, si esgrimimos que Maquiavelo es pre-moderno porque oponga al providencialismo cristiano un modelo de historia causal basado en la necesidad y la fortuna (ni enteramente fatalista, ni astrológicamente predecible); o porque carece de un esquema de progreso histórico; o porque desconfía del papel de la razón y del libre arbitrio en la psicología individual; o porque desconoce el valor de las virtudes morales como criterio para entender la historia en general y la actuación política individual, entonces, sólo habrá que añadir que, por esto mismo o por similares razones más de media modernidad es pre-moderna.

Una pregunta similar podría hacérsele a Villacañas, visto que éste afirma que la ceguera Maquiaveliana para comprender el potencial revitalizador del

Maquiavelo rupturista no gracias a su cosmología, sino a pesar de ella (op. cit., pp.64-65). En torno a la relación entre cosmología y política una interesante línea de trabajo es la abordada por M. E. Vatter en su erudito trabajo, donde se nos dice: "In Machiavelli freedom and history, rather than Nature or God, become the terms in which the difference between necessity and contingency is framed for the first time in modernity." (VATTER, op. cit., p. 193)

55 Así leemos en un seguidor de Parel: «Not only does it render Machiavelli decidely 'less modern', it also suggests that the 'amorality' or 'moral realism' of Machiavellian virtù must be regarded as an outcome of the cosmological view of reality belonging to his age.» p. 239 Sammy Basu, In a Crazy Time The Crazy Come Out Well: Machiavelli and the Cosmology of his Day, History of Political Thought, (1990, XI (2), pp. 213-239; pero también J. L. VILLACAÑAS, Excepcionalidad y modernidad, "principe nuovo" $y$ uvivere politico", en "La herencia de Maquiavelo. Modernidad y Voluntad de Poder», R. Rodriguez ARamayo y J. L. Villacañas (comps.), Mexico, 1999. Villacañas, en relación a la cuestión de la fortuna, asocia la premodernidad de Maquiavelo con el "valor emergente de la magia, que Maquiavelo rozó en algún pasaje de su vida,..." J. L. VillaCAÑAS, op. cit., p. 17. No sabría decir a qué se refiere exactamente Villacañas puesto que no se precisa más la cuestión. En cualquier caso, sobre el valor de la magia en Maquiavelo puede leerse el exhaustivo capítulo dedicado a la materia por A. SORELLA, que parece estar muy lejos de establecer un nexo entre los posibles intereses «mágicos» de Maquiavelo y su doctrina polírica o su doctrina en torno a la fortuna. Cf. A. SORELlA, Magia, lingua e commedia nel Machiavelli, Firenze 1990, pp. 77-88. 
espíritu cristiano, su "pre-cristianismo" ${ }^{56}$, es ya un signo de premodernidad; porque entonces sería también ceguera premoderna la del libertinismo europeo de los siglos venideros que, teniendo ante los ojos el "potencial revitalizador" del cristianismo reformado o contrarreformado, censura por igual todo celo religioso desde el partido de los ateístas, los políticos, los maquiavelistas.

Tampoco nos convence otro extremo interpretativo muy extendido y es aquél de quienes han creído ver en el autor florentino el fundador de la moderna ciencia política. Nosotros, por el contrario insistiremos en que, precisamente, la caracterización maquiaveliana de la fortuna representa sobre todo la negación de la política como ciencia rigurosa (predictiva), sea que asimilable por un sólo sujeto, sea que compartida por un colectivo de "virtuosos". Maquiavelo no es Hobbes. No hay en él la pretensión de fundar una ciencia política o moral exacta. El nuevo territorio descubierto no es la ciencia exacta, es el territorio de la política como ámbito específico y autónomo, como arte que debe combinar lo posible y lo necesario ${ }^{57}$. Estamos ante el rechazo del

56 Villacañas, art. cit., p. 30-1. Aceptando el anacronismo de la cuestión, creo que el punto esencial para Maquiavelo no es qué puede el cristianismo, tal vez bajo otras coordenadas, hacer en Inglaterra, Alemania o en la futura Europa. Lo esencial para Maquiavelo es ¿cuál ha sido y sigue siendo el papel del cristianismo en Italia? Y la respuesta es bastante clara: corrupción, debilidad, decadencia. Si se quiere forzar la imaginación, diremos que el mismo florentino halla ejemplos de cristianismo no "corruptor" (en las cruzadas, en el mismo Savonarola, en los primeros papas). Ahora bien, en algo no se anda con ambiguiedades: tanto el mensaje de Cristo "strictu sensu", cuanto la interpretación efectiva y mayoritaria que la Iglesia ha hecho de él son políticamente inservibles desde una lógica de la libertad republicana, y de la supervivencia y reforzamiento del Estado. Que, a la vuelta del siglo, se verifican otras posibilidades de encuadrar el trinomio religión-sociedad-Estado nadie lo puede negar; pero diremos que, en defensa de Maquiavelo, estas posibilidades se actuarán más bien pese a los Evangelios y pese a las Decretales que no gracias a ambos. En cuanto al "pre-cristianismo" maquiaveliano del que habla Villacarias, me parece que el quondam Secretario florentino hace méritos más que suficientes para que se le conceda el título que mejor le corresponde en relación a la religión de Pedro y Pablo: Maquiavelo no se sitúa en un planteamiento "pre-cristiano", sino sencillamente "anticristiano".

57 Aunque no compartimos, por razones que no vienen al caso, muchos de sus puntos, no dejan de ser interesantes en este sentido las fundadas apreciaciones de Ramón Má́z en torno a Il Príncipe en cuanto que mito fundador (en oposición a la teoricidad presente en autores como Hobbes) de la "politicidad" en sentido moderno, y del "arte de lo posible." $\mathrm{R}$. Maíz, Modernidad y Estado en Maquiavelo, en "Filosofía y ciencia en el Renacimiento" Simposio de la Universidad de Compostela [Nov. 1985], Compostela, 1988, pp. 273-300, aquí 298-300. 
moralismo y de los paradigmas armonicistas ${ }^{58}$ o utópicos que han dominado, desde la Antigüedad, el pensamiento político. El nuevo territorio es el realismo político con pretensiones de fidelidad al comportamiento objetivo de los hombres y al curso efectivo de la historia. Existe, sí, una regularidad, sea en la naturaleza humana, sea en la historia de los cuerpos políticos: es éste el territorio de la necesidad ${ }^{59}$, del que cabe un conocimiento más o menos seguro o al menos altamente probable; pero la inestabilidad, y el hecho de que mente humana tenga serias limitaciones para concebir la totalidad y necesidad del concursus causarum que determina una coyuntura particular, instala a su pensamiento político a distancia de la exactitud cientifica.

Se trata pues de una filosofía política que comparte con la actitud científica algunas de sus premisas: el rechazo del moralismo y del armonicismo, la voluntad de explicar los acontecimientos políticos y establecer hipótesis sobre su desarrollo a partir de las regularidades y reglas que nos concede la experiencia y la historia, etc. Pero el arte de la política carece tanto de la necesidad deductiva de la geometría como de los atributos empíricos o estadísticos en lo que se forjan las ciencias sociales. Se trata aquí de una fusión de teoría y praxis, pero una fusión en la que la teoría no termina de agotar todas las posibilidades de la praxis: precisamente porque una ciencia tiende a unas condiciones de imprecisión 0 , y porque la práctica política en el esquema maquiaveliano actúa siempre en condiciones de irreducible incertidumbre. Un arte, en fin, que incluye experiencia, conocimientos teóricos y pasión, y que encuentra quizá un cierto parecido durante el Renacimiento con el arte de la medicina ${ }^{60}$,

58 Rafael del Águila ha descrito con eficacia y concisión el predominio de la contingencia en el universo político maquiaveliano, en "un mundo sin principio reunificador ni armonizador alguno." (R DEL ÁGUILA, La senda del mal, Política y razón de Estado, Madrid 2000, p. 83. A ello yo simplemente insistiría en señalar que ésta es una de las más significativas rupturas de Maquiavelo con el pensamiento político clásico y medieval.

59 Sobre la importante cuestión de la necesidad, envío a quien tenga interés a la síntesis de Münkler (op. cit., pp. 246-250) quien no sin razón se lamenta de la infravaloración del concepto de necesidad en la economía de la obra maquiaveliana, reivindicando su protagonismo e importancia (ibid. p. 247). Münkler por ejemplo subraya que el énfasis maquiaveliano en la noción de necessita, no sólo se opone a la medieval providentia Dei, sino también al culto renacentista de la fortuna (ibid., p. 249)

60 De la política como eine Kunst zu lebren, en relación a la regularidad de la necesidad, ver MUNKLER, op. cit., p. 250, quien además subraya el carácter de la fortuna como uder Inbegriff der politischen Varaiblen." (Ibid., 302). A la comparación de la política maquiaveliana con el paradigma médico $\mathrm{L}$. Zanzi le ha dedicado un voluminoso libro con algunas páginas 
de no ser porque esta última carece, en principio, de toda pasión y resquicio azaroso.

A partir del cuadro maquiaveliano parece claro que no existe la posibilidad de eliminar toda contingencia histórica y política, no hay posibilidad de determinar constantemente el exacto devenir de la historia, entre otras razones, a causa del carácter conflictivo de la historia humana, fruto a su vez de la contraposición de ambiciones individuales y colectivas. Ahora bien, en modo alguno debe para Maquiavelo la política renunciar al conocimiento plausible de las regularidades y de la causación necesaria. $\mathrm{Ni}$, por lo demás, el objeto de Maquiavelo es sólo la descripción o análisis del ser: es la teorización del deber ser, un deber ser ajeno sin embargo a toda perspectiva moral: la libertad cifrada en autodeterminación política (cuando se trata de colectivos), la influencia efectiva en el curso de acontecimientos de acuerdo con los deseos particulares (cuando se trata de individuos). Este arte pretende proporcionar un conocimiento, limitado, sí; pero sin el cual, la política se convertiría en una actividad de consecuencias impredecibles. Así, aunque la sombra de la fortuna sobre lo humano significa la negación de la política como ciencia exacta, la teorizacíon de la virtud es la afirmación maquiaveliana de la política como el único territorio en el que el hombre, a pesar de sus esenciales limitaciones, puede proyectar sobre el desorden su única y casi nunca inocente libertad.

notables (L. ZANZI, I segni della natura e i paradigmi della storia: Il metodo del Machiavelli. Ricerche sulla logica scientifica degli umanisti tra medicina e storiografia, 1981 Manduria). Por ejemplo, las que se refieren al estatus gnoseológico de la medicina durante el Renacimiento (ZANZI, op. cit., pp. 114-129), o al parecido entre la metodología médica y la maquiaveliana (ibid., p. $83 ; 216-217,368$, etc.) Si se quiere una analogía más, Orestes Tommasini señaló en su momento el componente vitalístico de la virtud maquiaveliana, encontrando además bastantes similitudes con la concepción galeniana: "...né altro indica la parola virtù del politico fiorentino che quello che Galeno e i medici solevano designare con norme di virtus." (O. TOMMASINI, La vita e gli scritti di Nicollo Machiavelli, 2 Vols., Roma 1883, II vol., pp. 38-9). 